\title{
Extending of Edge Even Graceful Labeling of Graphs to Strong $r$-Edge Even Graceful Labeling
}

\author{
Mohamed R. Zeen El Deen $\mathbb{D i D}^{1}$ and Nora A. Omar ${ }^{2}$ \\ ${ }^{1}$ Department of Mathematics, Faculty of Science, Suez University, Suez, Egypt \\ ${ }^{2}$ Department of Mathematics, Faculty of Science, Port-Said University, Port Fuad, Egypt \\ Correspondence should be addressed to Mohamed R. Zeen El Deen; mohamed.zeeneldeen@suezuniv.edu.eg
}

Received 22 December 2020; Accepted 22 March 2021; Published 5 April 2021

Academic Editor: Antonio Di Crescenzo

Copyright ( 2021 Mohamed R. Zeen El Deen and Nora A. Omar. This is an open access article distributed under the Creative Commons Attribution License, which permits unrestricted use, distribution, and reproduction in any medium, provided the original work is properly cited.

\begin{abstract}
Edge even graceful labeling of a graph $G$ with $p$ vertices and $q$ edges is a bijective $f$ from the set of edge $E(G)$ to the set of positive integers $\{2,4, \ldots, 2 q\}$ such that all the vertex labels $f^{*}[V(G)]$, given by $f^{*}(u)=\left(\sum_{u v \in E(G)} f(u v)\right) \bmod (2 k)$, where $k=\max (p, q)$, are pairwise distinct. There are many graphs that do not have edge even graceful labeling, so in this paper, we have extended the definition of edge even graceful labeling to $r$-edge even graceful labeling and strong $r$-edge even graceful labeling. We have obtained the necessary conditions for more path-related graphs and cycle-related graphs to be an $r$-edge even graceful graph. Furthermore, the minimum number $r$ for which the graphs: tortoise graph, double star graph, ladder and diagonal ladder graphs, helm graph, crown graph, sunflower graph, and sunflower planar graph, have an $r$-edge even graceful labeling was found. Finally, we proved that the even cycle $C_{2} n$ has a strong 2-edge even graceful labeling when $n$ is even.
\end{abstract}

\section{Introduction and Preliminaries}

The field of graph theory plays vital role in various mathematical fields which are used in structural models. This structural arrangement of various objects or technologies lead to new inventions and modifications in the existing environment for improvement in these fields. Nowadays, graph labeling has become an important and rich branch of different research studies in graph theory because of its huge applications in many disciplines, e.g., coding theory, X-ray, crystallography, radar, communication networks, astronomy, communication network addressing, circuit design, and graph decomposition problems. For more interesting applications of graph labeling, see [1-3].

Throughout this paper, a graph $G=(V(G), E(G))$ always means a finite and a simple connected graph (without loops and parallel edges), where $q=|E(G)|$ is the cardinality of $E(G)$ and $p=|V(G)|$ is that of $V(G)$.

There are two main types of graceful labeling in graph theory. The oldest one is the vertex graceful labeling and the recent one is the edge graceful labeling. Here we are dealing with the recent one.

A function $f$ is called an edge graceful labeling of a graph $G$ if $f: E(G) \longrightarrow\{1,2, \ldots, q\}$ is bijective and the induced function $f^{*}: V(G) \longrightarrow\{0,1,2, \ldots, p-1\}$, defined as $f^{*}(u)=\left(\sum_{x y \in E(G)} f(x y)\right) \bmod (p)$, is bijective. This type of graph labeling was first introduced by Lo in 1985 [4].

A function $f$ is called an edge odd graceful labeling of a graph if $f: E(G) \longrightarrow\{1,3, \ldots, 2 q-1\}$ is bijective and the induced function $f^{*}: V(G) \longrightarrow\{0,1,2,3, \ldots, 2 q-1\}$, defined as $f^{*}(u)=\left(\sum_{x y \in E(G)} f(x y)\right) \bmod (2 q)$, is bijective. This type of graph labeling was first introduced by Solairaju and Chithra in 2009 [5] (see also [6, 7]).

A function $f$ is called an edge even graceful labeling of a graph $G$ if $f: E(G) \longrightarrow\{2,4, \ldots, 2 q\}$ is bijective and the induced function $f^{*}: V(G) \longrightarrow\{0,2,4, \ldots, 2 q\}$, defined as $f^{*}(x)=\left(\sum_{x y \in E(G)} f(x y)\right) \bmod (2 k)$, is an injective function, where $k=\max (p, q)$. This type of graph labeling was first introduced by Elsonbaty and Daoud in $2017[8,9]$. They introduced some path- and cycle-related graphs which are edge even graceful. Following this, Daoud [10] investigated 
the edge even graceful labeling of polar grid graphs and Zeen El Deen et al. [11-13] studied more graphs having an edge even graceful labeling. The graph that admits an edge even graceful labeling is called an edge even graceful graph.

A summary of the results on these three types of graceful labels as well as all known labels so far can be found in [14].

Because there are many graphs which do not have edge even graceful labeling, we introduce the extension of the definition of edge even graceful labeling to $r$-edge even graceful labeling.

Definition 1. A function $f$ is called $r$-edge even graceful labeling of the graph $G$ if $f: E(G) \longrightarrow\{2,4, \ldots, 2 q+2 r-2\}$ is an injective function such that the induced mapping $f^{*}: V(G) \longrightarrow\{0,2,4$, $\ldots, 2 q+2 r-2\}$, given by: $f^{*}(x)=\left(\sum_{x y \in E(G)} f(x y)\right)$ $\bmod (2 k+2 r-2)$, is an injective function, where $k=\max (p, q)$. We will call the graph that admits $r$-edge even graceful labeling an $r$-edge even graceful graph.

Note that the standard definition of edge even graceful labeling corresponds to a 1-edge even graceful labeling.

Definition 2. A function $f$ is called strong $r$-edge even graceful labeling of the graph $G$ if $f: E(G) \longrightarrow\{2,4, \ldots$, $2 q+2 r-2\}$ is an injective function such that the induced mapping $f^{*}: V(G) \longrightarrow\{2 r-2,2 r, 2 r+2, \ldots, 2 q+2 r-2\}$, given by $f^{*}(x)=\left(\sum_{x y \in E(G)} f(x y)\right) \bmod (2 k+2 r-2)$, is an injective function, where $k=\max (p, q)$.
Illustration. A 2-edge even and a strong 2-edge even labeling of the graph $K_{4}$ is shown in Figure 1 .

\section{The $r$-Edge Even Graceful Labeling for Some Path-Related Graphs}

2.1. The r-Edge Even Graceful Labeling of the Path Graph $P_{n}$. The path graph $P_{n}$ has edge even graceful labeling only when $n$ is an odd number [8].

Theorem 1. When $n$ is an even number, the path graph $P_{n}$ has 3-edge even graceful labeling.

Proof. The path graph $P_{n}$ has $p=n$ vertices and $q=n-1$ edges. Let $e_{i}$ denote the edge $v_{i} v_{(i+1)}$ in $P_{n}$ (see Figure 2).

Let $r=3$; then, $2 p+2 r-2=2 n+4$, and there are two cases.

(i) Case (1). If $n \equiv 0 \bmod 4$, we define the labeling function $f: E\left(P_{n}\right) \longrightarrow\{2,4, \ldots, 2 n+2\}$ as follows:

$$
f\left(e_{i}\right)= \begin{cases}i+1, & \text { if } i=1,3,5, \ldots, n-1, \\ n+i, & \text { if } i=2,4, \ldots, \frac{n}{2} \\ n+i+4, & \text { if } i=\frac{n}{2}+2, \frac{n}{2}+4, \ldots, n-2 .\end{cases}
$$

Now, the labeling of the vertices is

$$
\begin{aligned}
& f^{*}\left(v_{1}\right)=f\left(e_{1}\right)=2, \quad f^{*}\left(v_{n}\right)=\left[f\left(e_{n-1}\right)\right] \bmod (2 n+4)=n, \\
& f^{*}\left(v_{i}\right)=\left[f\left(e_{i}\right)+f\left(e_{i-1}\right)\right] \bmod (2 n+4)=(n+2 i) \bmod (2 n+4), \quad i=2,3, \ldots, \frac{n}{2}+1, \\
& f^{*}\left(v_{i}\right)=\left[f\left(e_{i}\right)+f\left(e_{i-1}\right)\right] \bmod (2 n+4)=(n+2 i+4) \bmod (2 n+4), \quad i=\frac{n}{2}+2, \frac{n}{2}+3, \ldots, n-1 .
\end{aligned}
$$

So, the labels of the vertices $v_{2}, v_{3}, \ldots, v_{(n / 2)}, v_{(n / 2)+1}$ will be $n+4, n+6, \ldots, 2 n, 2 n+2$, respectively, and the labels of the vertices $v_{(n / 2)+2}, v_{(n / 2)+3}$, $\ldots, v_{n-2}, v_{n-1} \quad$ will be $4,6, \ldots, n-4, n-2$, respectively.

$$
f\left(e_{i}\right)=\left\{\begin{array}{l}
i+1, \quad \text { if } i=1,3,5, \ldots, n-1, \\
n+i, \quad \text { if } i=2,4, \ldots, \frac{n}{2}+1, \\
n+i+4, \quad \text { if } i=\frac{n}{2}+3, \frac{n}{2}+5, \ldots, n-2 .
\end{array}\right.
$$

(ii) Case (2). If $n \equiv 2 \bmod 4$, we define the labeling $f$ as follows:

Now, the labeling of the vertices is

$$
\begin{aligned}
f^{*}\left(v_{1}\right) & =f\left(e_{1}\right)=2, \quad f^{*}\left(v_{n}\right)=\left[f\left(e_{n-1}\right)\right] \bmod (2 n+4)=n, \\
f^{*}\left(v_{i}\right) & =\left[f\left(e_{i}\right)+f\left(e_{i-1}\right)\right] \bmod (2 n+4)=(n+2 i) \bmod (2 n+4), \quad i=2,3, \ldots, \frac{n}{2}+2, \\
f^{*}\left(v_{i}\right) & =\left[f\left(e_{i}\right)+f\left(e_{i-1}\right)\right] \bmod (2 n+4)=(n+2 i+4) \bmod (2 n+4), \quad i=\frac{n}{2}+3, \frac{n}{2}+4, \ldots, n-1 .
\end{aligned}
$$




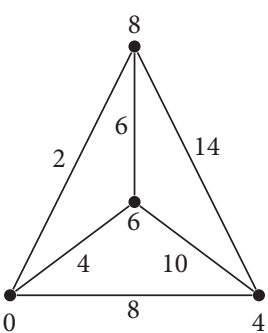

(a)

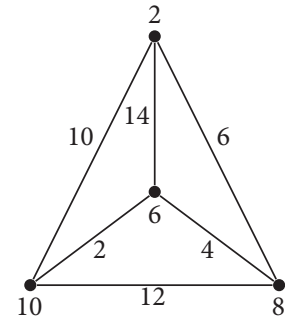

(b)

Figure 1: (a) A 2-edge even graceful labeling for $K_{4}$. (b) A strong 2-edge even graceful labeling for $K_{4}$.

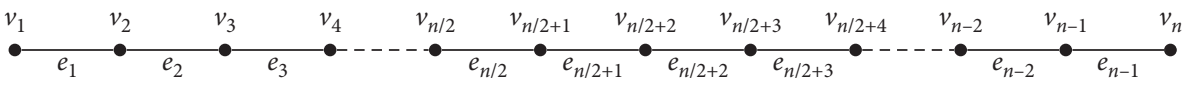

Figure 2: The path graph $P_{n}$ with ordinary labeling when $n$ is even.

So, the labels of the vertices $v_{2}, v_{3}, \ldots, v_{(n / 2)}$, $v_{(n / 2)+1}, v_{(n / 2)+2}$ are $n+4, n+6, \ldots, 2 n, 2 n+2,0$, respectively, and the labels of the vertices $v_{(n / 2)+2}, v_{(n / 2)+3}$, $\ldots, v_{n-2}, v_{n-1}$ are $6,8, \ldots, n-4, n-2$ respectively.

Therefore, all the vertex labels are even and distinct numbers. Thus, the path graph $P_{n}$ has 3 -edge even graceful labeling when $n$ is even.

Illustration. A 3-edge even graceful labeling of the graphs $P_{12}$ and $P_{14}$ is shown in Figure 3.

2.2. The r-Edge Even Graceful Labeling of the Star Graph $K_{1, n}$. It should be noted that the star graph $K_{1, n}$ has edge even graceful labeling only when $n$ is an even number [8].

Theorem 2. The star graph $K_{1, n}$ has 3-edge even graceful labeling when $n$ is odd.

Proof. The graph $K_{1, n}$ has $p=n+1$ vertices and $q=n$ edges obtained by connecting one vertex $v_{0}$ with each of the $v_{i}$, where $1 \leq i \leq n$. Let $r=3$; then, $2 p+2 r-2=2 n+6$, and we define the labeling $f: E\left(K_{1, n}\right) \longrightarrow\{2,4, \ldots, 2 n+4\}$ as follows:

$$
f\left(v_{0} v_{i}\right)=\left\{\begin{array}{l}
2 i, \quad \text { if } i=1,2,3, \ldots, \frac{n+3}{2}, \\
2 i+2, \quad \text { if } i=\frac{n+5}{2}, \ldots, n .
\end{array}\right.
$$

Note that we do not take the labels $n+5$ and $2 n+4$ in the label of edges. Since the vertices $v_{i}, i=1,2,3, \ldots, n$ are pendant, then $f^{*}\left(v_{i}\right)$ take their edge labels which are even and distinct and

$$
\begin{aligned}
f^{*}\left(v_{0}\right) & =\left[\sum_{i=1}^{n} f\left(v_{0} v_{i}\right)\right] \bmod (2 n+6) \\
& =\left[\sum_{i=1}^{(n+3) / 2}(2 i)+\sum_{i=(n+5) / 2}^{n}(2 i+2)\right] \bmod (2 n+6)=0 .
\end{aligned}
$$

Hence, the labels of the vertices are all even and distinct numbers.

Illustration. A 3-edge even labeling of the graph $K_{1,11}$ is shown in Figure 4.

\subsection{The r-Edge Even Graceful Labeling of the Comb Graph} $P_{n} \odot K_{1}$

Theorem 3. The comb graph [15] $P_{n} \odot K_{1}$ has 3-edge even graceful labeling for any positive integer $n$.

Proof. The graph $P_{n} \odot K_{1}$ has $p=2 n$ vertices and $q=2 n-1$ edges. Let the comb graph $P_{n} \odot K_{1}$ be given as indicated in Figure 5.

Let $r=3$; then, $2 p+2 r-2=4 n+4$, and we define the labeling $f: E\left(P_{n} \odot K_{1}\right) \longrightarrow\{2,4, \ldots, 4 n+2\}$ as follows:

$$
\begin{aligned}
& f\left(a_{i}\right)=4 n-2 i+2, \quad \text { if } i=1,2, \ldots, n, \\
& f\left(b_{i}\right)=2 i+2, \quad \text { if } i=1,2, \ldots, n-1 .
\end{aligned}
$$

Then, the induced vertex labels are

$$
\begin{aligned}
& f^{*}\left(v_{1}\right)=\left[f\left(a_{1}\right)+f\left(b_{1}\right)\right] \bmod (4 n+4)=0, \\
& f^{*}\left(v_{n}\right)=\left[f\left(a_{n}\right)+f\left(b_{n-1}\right)\right] \bmod (4 n+4)=4 n+2, \\
& f^{*}\left(v_{i}\right)=\left[f\left(b_{i}\right)+f\left(b_{i-1}\right)+f\left(a_{i}\right)\right] \bmod (4 n+4)=2 i, \\
& \text { for } i=2, \ldots, n-1 .
\end{aligned}
$$

So, the labels of the vertices $v_{2}, v_{3}, v_{4}, \ldots, v_{n-1}$ are $4,6,8, \ldots, 2 n-2$, respectively. Again, each pendant vertex will take the labels of its edges; then, $f^{*}\left(u_{i}\right)=f\left(a_{i}\right)=4 n-$ $2 i+2, \forall i=1,2,3, \ldots, n$ which are even and distinct from all the labels of the vertices $v_{i}$. Hence, the comb graph $P_{n} \odot K_{1}$ has 3-edge even graceful labeling for any number $n$. 


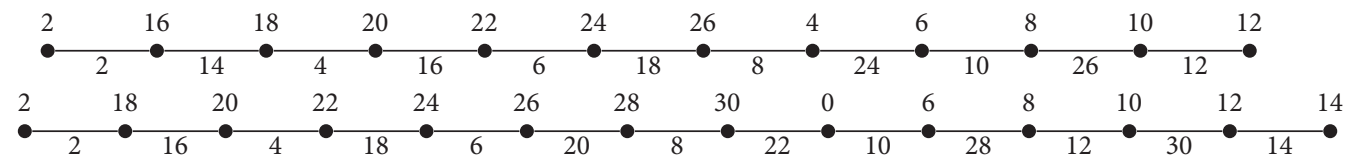

Figure 3: A 3-edge even graceful labeling of the path graphs $P_{12}$ and $P_{14}$.

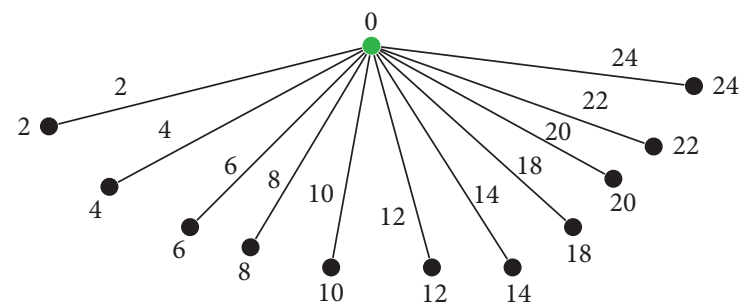

FIgURE 4: A 3-edge even labeling of the graph $K_{1,11}$.

Illustration. A 3-edge even labeling of the comb graph $P_{10} \odot K_{1}$ is shown in Figure 6 .

2.4. The r-Edge Even Graceful Labeling of the Graph $T_{n, n-2}$. The graph $T_{n, n-2}$ obtained from a path $P_{n}$ by attaching exactly one pendant edge to each internal vertex of the path $P_{n}$, i.e., $T_{n, n-2}$, has vertices $\left\{v_{i}, u_{j}, i=1,2, \ldots, n, j=\right.$ $1,2, \ldots, n-2\} \quad$ and edges $\left\{v_{i} v_{i+1}, u_{j} v_{j+1}, i=1,2, \ldots\right.$, $n-1, j=1,2, \ldots, n-2\}$.

Theorem 4. The graph $T_{n, n-2}$ has 3-edge even graceful labeling for all positive integer $n \geq 4$.

Proof. The graph $T_{n, n-2}$ has $p=2 n-2$ vertices and $q=2 n-$ 3 edges (see Figure 7 ).

Let $r=3$; then, $2 p+2 r-2=4 n$. The labeling $f: E\left(T_{n, n-2}\right) \longrightarrow\{2,4, \ldots, 4 n-2\}$ can be defined as follows:

$$
\begin{aligned}
& f\left(u_{i} v_{i+1}\right)=f\left(a_{i}\right)= \begin{cases}4 n-2 i, & \text { if } i=1,2, \ldots, n-3, \\
2 n+2, & \text { if } i=n-2,\end{cases} \\
& f\left(v_{i} v_{i+1}\right)=f\left(b_{i}\right)= \begin{cases}2 i, & \text { if } i=1,2, \ldots, n-2, \\
2 n, & \text { if } i=n-1 .\end{cases}
\end{aligned}
$$

Note that we do not take the labels $2 n-2$ and $2 n+4$ in the label of edges.

Then, the induced vertex labels are

$$
\begin{array}{r}
f^{*}\left(v_{1}\right)=f\left(b_{1}\right)=2, \quad f^{*}\left(v_{n}\right)=f\left(b_{n-1}\right)=2 n-2, \\
f^{*}\left(v_{i}\right)=\left[f\left(b_{i}\right)+f\left(b_{i-1}\right)+f\left(a_{i-1}\right)\right] \bmod (4 n)=2 i, \\
\text { for } i=2, \ldots, n-2 .
\end{array}
$$

So, the labels of the vertices $v_{2}, v_{3}, v_{4}, \ldots, v_{n-2}$ are $4,6,8, \ldots, 2 n-4$, respectively, which are all even and distinct numbers. Once again, since the vertices $u_{i}$ are pendant, then $f^{*}\left(u_{i}\right), i=1,2, \ldots, n-2$ take their edge labels. Therefore, there is no repetition of the labels, and $T_{n, n-2}$ has 3-edge even graceful labeling for all $n$.

Illustration. A 3-edge even labeling of the graph $T_{9,7}$ is shown in Figure 8.

2.5. The r-Edge Even Graceful Labeling of the Double Star $B_{n, m}$. The double star is the graph obtained by joining the center of two stars $K_{1, n}$ and $K_{1, m}$ with an edge, denoted by $B_{n, m}$. The number of vertices is $p=n+m+2$, and the number of edges is $q=n+m+1$. The double star $B_{n, m}$ has edge even graceful labeling when one of $(m$ or $n)$ is an odd number and the other is an even number [11].

\section{Theorem 5}

(1) The double star $B_{n, m}$ is 2-edge even graceful graph when both $m$ and $n$ are odd numbers.

(2) The double star $B_{n, m}$ is 3-edge even graceful graph when both $m$ and $n$ are even numbers.

Proof. Let the vertex and edge symbols be given as in Figure 9.

Case (1). If $m$ and $n$ are odd numbers. Let $r=2$; then, $2 q+2 r-2=2 m+2 n+4$.

We define the labeling function $f: E(G) \longrightarrow\{2,4, \ldots, 2 m+2 n+4\}$ as follows:

$$
f(u v)=2 \text {, }
$$

$f\left(e_{i}\right)=2 i+2, \quad$ for $i=1,2, \ldots, \frac{m-1}{2}$,

$f\left(E_{i}\right)=2 m+2 n+6-2 i, \quad$ for $i=1,2, \ldots, \frac{m+1}{2}$,

$f\left(a_{i}\right)=m+1+2 i, \quad$ for $i=1,2, \ldots, \frac{n+1}{2}$,

$f\left(b_{i}\right)=(m+2 n+5)-2 i, \quad$ for $i=1,2, \ldots, \frac{n-1}{2}$. 


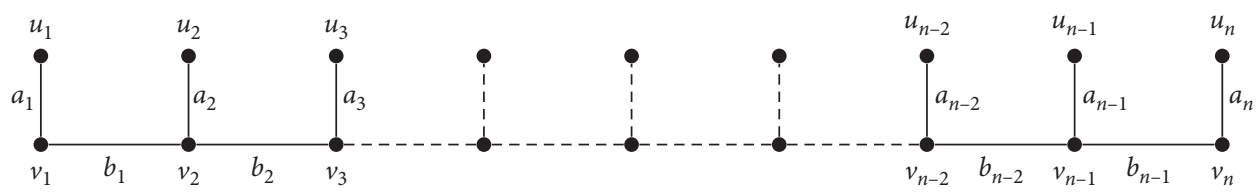

FIgURE 5: The comb graph $P_{n} \odot K_{1}$ with ordinary labeling.

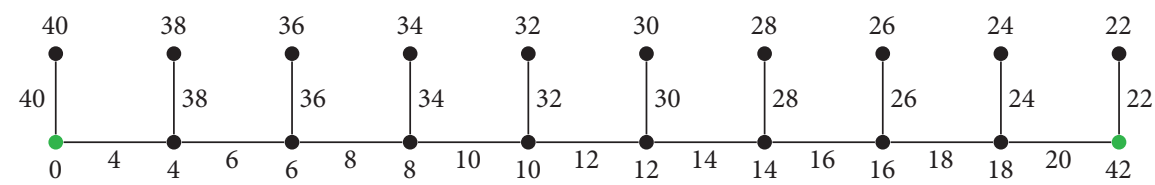

Figure 6: A 3-edge even labeling of the comb graph $P_{10} \odot K_{1}$.

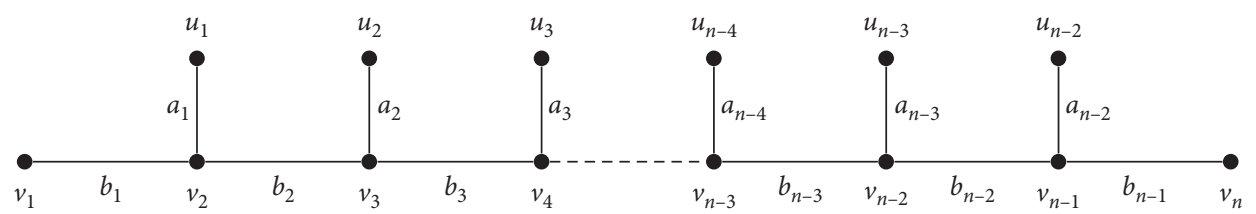

FIGURE 7: The graph $T_{n, n-2}$ with ordinary labeling.

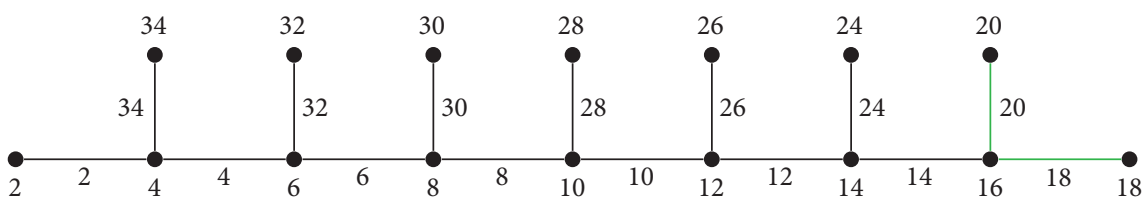

Figure 8: A 3-edge even labeling of the graph $T_{9,7}$.

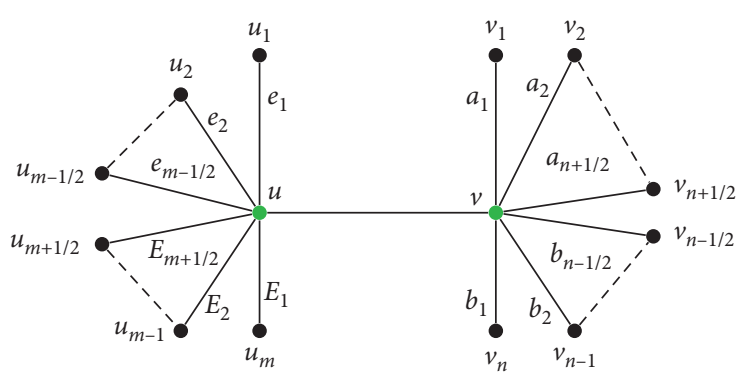

(a)

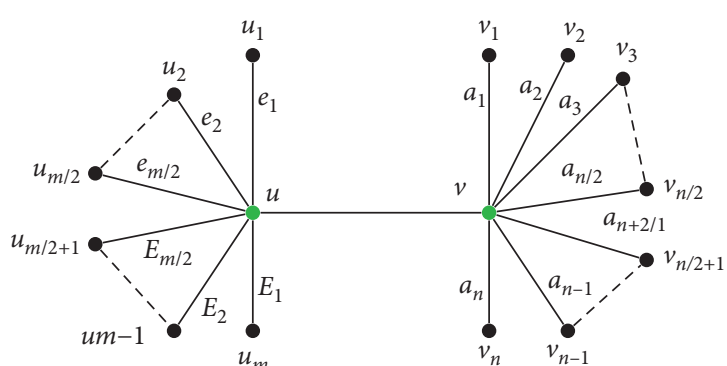

(b)

Figure 9: (a) $B_{m, n}$ when $m$ and $n$ are odd numbers. (b) $B_{m, n}$ when $m$ and $n$ are even numbers.

In this labeling, we can note that

(i) $\left[f\left(e_{i}\right)+f\left(E_{i+1}\right)\right] \bmod (2 m+2 n+6) \equiv 0 \bmod$ $(2 m+2 n+6)$, for $i=1,2, \ldots,(m-1 / 2)$.

(ii) $\left[f\left(a_{i}\right)+f\left(b_{i}\right)\right] \bmod (2 m+2 n+6) \equiv 0 \bmod$ $(2 m+2 n+6)$, for $i=1,2, \ldots,(n-1 / 2)$. (iii) $\left[f(u v)+f\left(E_{1}\right)\right] \bmod (2 m+2 n+6) \equiv 0 \bmod$ $(2 m+2 n+6)$.

So, the vertex labels will be

$$
\begin{aligned}
f^{*}(u) & =\left[\sum_{i=1}^{(m-1) / 2} f\left(e_{i}\right)+\sum_{i=1}^{(m+1) / 2} f\left(E_{i}\right)+f(u v)\right] \bmod (2 m+2 n+6)=0, \\
f^{*}(v) & =\left[\sum_{i=1}^{(n-1) / 2} f\left(b_{i}\right)+\sum_{i=1}^{(n-1) / 2} f\left(a_{i}\right)+f\left(a_{(n+1) / 2}\right)+f(u v)\right] \bmod (2 m+2 n+6)=m+n+4 .
\end{aligned}
$$


Each pendant vertex takes the labels of its incident edge which are different from $f^{*}(u)$ and $f^{*}(v)$.

Case (2). If $m$ and $n$ are even numbers. Let $r=3$; then, $2 q+2 r-2=2 m+2 n+6$. Consider the vertex and edge symbols given in Figure $9(\mathrm{~b})$. We define the mapping $f:(G) \longrightarrow\{2,4, \ldots, 2 m+2 n+6\}$ as follows: $f(u v)=2, f\left(e_{i}\right)=2 i+2 \quad$ for $\quad i=1,2, \ldots,(m / 2)$, $f\left(E_{i}\right)=2 p-2(i-1)$ for $i=1,2, \ldots,(m / 2)$

$$
f\left(a_{i}\right)= \begin{cases}m+2+2 i, & \text { if } i=1,2, \ldots, \frac{n}{2}+1, \\ (m+4)+2 i, & \text { if } i=\frac{n}{2}+2, \ldots, n .\end{cases}
$$

In this labeling, we can see that

(i) $\left[f\left(e_{i}\right)+f\left(E_{i}\right)\right] \bmod (2 m+2 n+8) \equiv 0 \bmod (2 m+$ $2 n+8)$, for $i=1,2, \ldots,(m / 2)$.

(ii) $\left[f\left(a_{i}\right)+f\left(a_{n-i+1}\right)\right] \bmod (2 m+2 n+8) \equiv 0 \bmod$ $(2 m+2 n+8)$, for $i=1,2, \ldots,(n / 2)-1$.

So, the vertex labels will be

$$
\begin{aligned}
f^{*}(u) & =\left[\sum_{i=1}^{(m / 2)} f\left(e_{i}\right)+\sum_{i=1}^{(m / 2)} f\left(E_{i}\right)+f(u v)\right] \bmod (2 m+2 n+8)=f(u v)=2, \\
f^{*}(v) & =\left[\sum_{i=1}^{(n / 2)-1} f\left(a_{n-i+1}\right)+\sum_{i=1}^{(n / 2)-1} f\left(a_{i}\right)+f\left(a_{(n / 2)}\right)+f\left(a_{(n / 2)+1}\right)+f(u v)\right] \bmod (2 m+2 n+8)=0 .
\end{aligned}
$$

Also, each pendant vertex takes the labels of its incident edge. Thus, we get a 3 -edge even graceful graph.

Illustration. A 2-edge even labeling of the star graph $B_{9,7}$ and 3 -edge even labeling of the star graph $B_{10,8}$ are shown in Figure 10.

\subsection{The r-Edge Even Graceful Labeling of the Ladder Graph $L_{n}=P_{2} \times P_{n}$}

Theorem 6. The ladder graph $L_{n}=P_{2} \times P_{n}$ has 2-edge even graceful labeling.
Proof. The graph $L_{n}$ has $p=2 n$ vertices and $q=3 n-2$ edges. Let $r=2$; then, $2 q+2 r-2=6 n-2$.

Consider the ladder graph $L_{n}=P_{2} \times P_{n}$ shown in Figure 11.

We define the labeling function $f: E\left(L_{n}\right) \longrightarrow$ $\{2,4, \ldots, 6 n-2\}$ as follows:

$$
\begin{aligned}
f\left(a_{i}\right) & =2 i, \quad i=1,2, \ldots, n, \\
f\left(c_{i}\right) & =6 n-2 i-2, \quad i=1,2, \ldots, n-1, \\
f\left(b_{i}\right) & =\left\{\begin{array}{l}
4 n-2 i-2, \quad \text { if } i=1,2, \ldots, n-2, \\
6 n-2, \quad \text { if } i=n-1 .
\end{array}\right.
\end{aligned}
$$

Then, the induced vertex labels are

$$
\begin{aligned}
f^{*}\left(v_{1}\right) & =\left[f\left(a_{1}\right)+f\left(c_{1}\right)\right] \bmod (6 n-2)=0, \\
f^{*}\left(v_{n}\right) & =\left[f\left(a_{n}\right)+f\left(c_{n-1}\right)\right] \bmod (6 n-2)=2, \\
f^{*}\left(v_{i}\right) & =\left[f\left(c_{i}\right)+f\left(c_{i-1}\right)+f\left(a_{i}\right)\right] \bmod (6 n-2)=6 n-2 i, \quad i=2, \ldots, n-1, \\
f^{*}\left(u_{1}\right) & =\left[f\left(a_{1}\right)+f\left(b_{1}\right)\right] \bmod (6 n-2)=4 n-2, \\
f^{*}\left(u_{n-1}\right) & =\left[f\left(a_{n-1}\right)+f\left(b_{n-1}\right)+f\left(b_{n-2}\right)\right] \bmod (6 n-2)=4 n, \\
f^{*}\left(u_{n}\right) & =\left[f\left(a_{n}\right)+f\left(b_{n-1}\right)\right] \bmod (6 n-2)=2 n, \\
f^{*}\left(u_{i}\right) & =\left[f\left(b_{i}\right)+f\left(b_{i-1}\right)+f\left(a_{i}\right)\right] \bmod (6 n-2)=2 n-2 i, \quad i=2, \ldots, n-2 .
\end{aligned}
$$

So, the labels of the vertices $v_{2}, v_{3}, \ldots, v_{n-2}, v_{n-1}$ will be $6 n-4,6 n-6, \ldots, 4 n+4,4 n+2$, respectively, and the labels of the vertices $u_{2}, u_{3}, \ldots, u_{n-3}, u_{n-2}$ will be $2 n-4,2 n-6, \ldots, 6,4$, respectively. Clearly, all the labels of the vertices are even and there is no repetition on the labels. Hence, the ladder graph $L_{n}$ has 2-edge even graceful labeling.
Illustration. A 2-edge even labeling of the ladder graph $L_{10}$ is shown in Figure 12.

2.7. The r-Edge Even Graceful Labeling of the Diagonal Ladder $D L_{n}$. Diagonal ladder graph is a ladder with additional edges $v_{i} u_{i+1}$ and $u_{i} v_{i+1}, i=1,2, \ldots, n-1$, denoted by $\mathrm{DL}_{n}$, where $n$ 


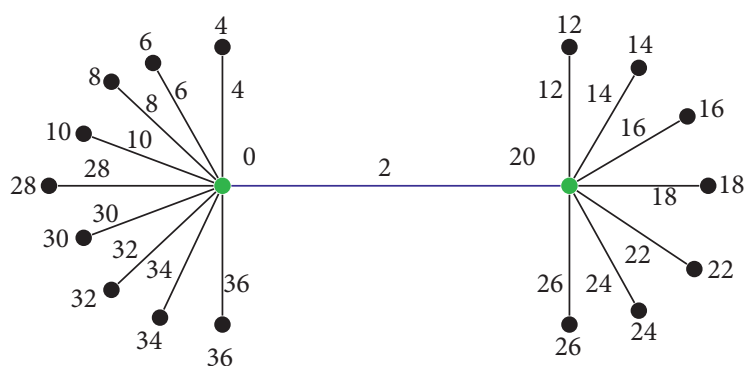

(a)

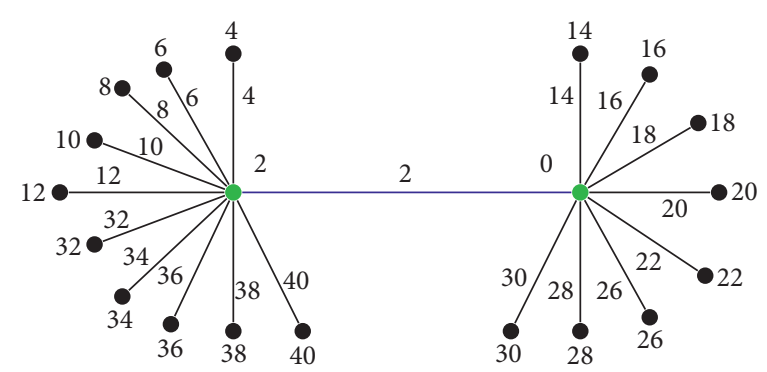

(b)

Figure 10: (a) A 2-edge even labeling of $B_{9,7}$ (b) A 3-edge even labeling of $B_{10,8}$.

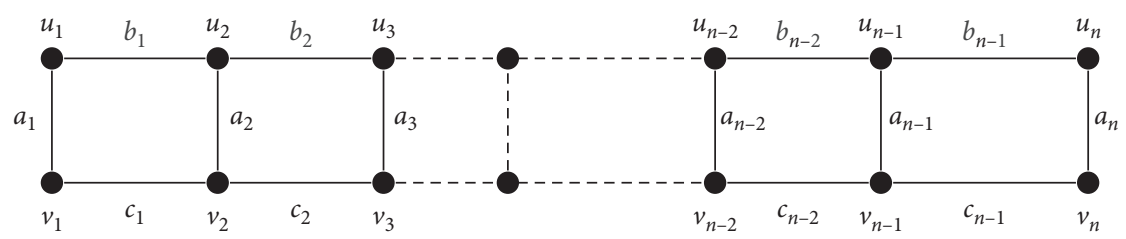

Figure 11: The ladder graph $L_{n}=P_{2} \times P_{n}$ with ordinary labeling.

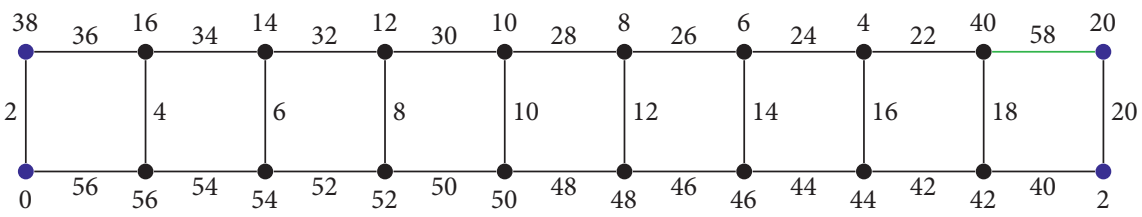

FIgURE 12: A 2-edge even labeling of the ladder graph $L_{10}=P_{2} \times P_{10}$.

is half its vertices and the number of vertices $\left|V\left(\mathrm{DL}_{n}\right)\right|=2 n$ and edges $\left|E\left(\mathrm{DL}_{n}\right)\right|=5 n-4$.

Theorem 7. The diagonal ladder $D L_{n}$ has 2-edge even graceful labeling.

Proof. Consider the diagonal ladder $\mathrm{DL}_{n}$ shown in Figure 13. Let $r=2$; then, $2 q+2 r-2=10 n-6$.

The labeling $f: E\left(\mathrm{DL}_{n}\right) \longrightarrow\{2,4, \ldots, 10 n-6\}$ can be defined as follows:

$$
\begin{aligned}
f\left(v_{i} u_{i+1}\right) & =2 i, \quad i=1,2, \ldots, n-1, \\
f\left(v_{i+1} u_{i}\right) & =2 n+2 i, \quad i=1,2, \ldots, n-1, \\
f\left(v_{i} v_{i+1}\right) & =10 n-6-2 i, \quad i=1,2, \ldots, n-1, \\
f\left(u_{i} u_{i+1}\right) & =8 n-4-2 i, \quad i=1,2, \ldots, n-1, \\
f\left(v_{i} u_{i}\right) & = \begin{cases}10 n-6, & \text { if } i=1, \\
6 n-2 i, & \text { if } i=2,3, \ldots, n .\end{cases}
\end{aligned}
$$

$$
\begin{aligned}
& f^{*}\left(v_{i}\right)=\left[f\left(v_{i} v_{i-1}\right)+f\left(v_{i} v_{i+1}\right)+f\left(v_{i} u_{i}\right)+f\left(v_{i} u_{i+1}\right)+f\left(v_{i} u_{i-1}\right)\right] \bmod (10 n-6)=8 n-2 i, \\
& f^{*}\left(u_{i}\right)=\left[f\left(u_{i} u_{i-1}\right)+f\left(u_{i} u_{i+1}\right)+f\left(v_{i} u_{i}\right)+f\left(u_{i} v_{i+1}\right)+f\left(u_{i} v_{i-1}\right)\right] \bmod (10 n-6)=4 n+4-2 i
\end{aligned}
$$




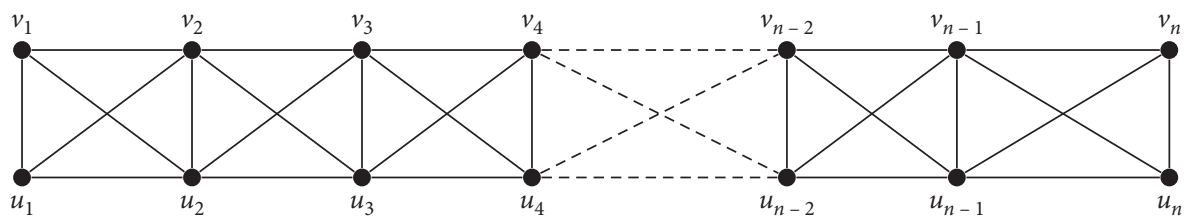

Figure 13: The diagonal ladder $\mathrm{DL}_{n}$ with ordinary labeling.

So, the labels of the vertices $v_{2}, v_{3}, \ldots, v_{n-2}, v_{n-1}$ are $8 n-4,8 n-6, \ldots, 6 n+4,6 n+2$, respectively, and the labels of the vertices $u_{2}, u_{3}, \ldots, u_{n-2}, u_{n-1}$ are $4 n, 4 n-2, \ldots$, $2 n+8,2 n+6$, respectively, and

$$
\begin{aligned}
& f^{*}\left(v_{n}\right)=\left[f\left(v_{n} v_{n-1}\right)+f\left(v_{n} u_{n}\right)+f\left(v_{n} u_{n-1}\right)\right] \bmod (10 n-6)=6 n, \\
& f^{*}\left(u_{n}\right)=\left[f\left(u_{n} u_{n-1}\right)+f\left(v_{n} u_{n}\right)+f\left(u_{n} v_{n-1}\right)\right] \bmod (10 n-6)=2 n+2 .
\end{aligned}
$$

Clearly, all the labels of the vertices are even and distinct, and thus we get the result.

Illustration. A 2-edge even labeling of the diagonal ladder $\mathrm{DL}_{8}$ is shown in Figure 14.

2.8. The $r$-Edge Even Graceful Labeling of the Tortoise Graph $T_{n}$. The tortoise graph $T_{n}$ is the graph obtained from a path $P_{n}$, where $n$ is odd, by attaching an edge between $v_{i}$ and $v_{n-i+1}$ for $1 \leq i \leq[n / 2]$, so $V\left(T_{n}\right)=V\left(P_{n}\right)$ and $E\left(T_{n}\right)=E\left(P_{n}\right) \cup$ $\left\{e_{i}=v_{i} v_{n-i+1}, i=n, n-1, \ldots,(n+3 / 2)\right\}$.

Theorem 8. The tortoise graph $T_{n}$ has 2-edge even graceful labeling.

Proof. The graph $T_{n}$ has $n$ vertices and $q=3(n-1) / 2$ edges.

Consider the tortoise graph $T_{n}$ shown in Figure 15.
Let $r=2$; then, $2 q+2 r-2=3 n-1$, and we define the labeling $f: E\left(T_{n}\right) \longrightarrow\{2,4, \ldots, 3 n-1\}$ as follows:

$$
f\left(e_{i}\right)=\left\{\begin{array}{l}
2 i, \quad \text { if } i=1,2,3, \ldots, \frac{n+1}{2}, \\
3 n-2 i+1, \quad \text { if } i=\frac{n+3}{2}, \ldots, n-1, \\
3 n-1, \quad \text { if } i=n, \\
5 n-2 i-1, \quad \text { if } i=n+1, n+2, \ldots, \frac{3(n-1)}{2} .
\end{array}\right.
$$

In view of the above labeling pattern, we have

$$
\begin{aligned}
f^{*}\left(v_{1}\right) & =\left[f\left(e_{1}\right)+f\left(e_{n}\right)\right] \bmod (3 n-1)=2, \\
f^{*}\left(v_{n}\right) & =\left[f\left(e_{n}\right)+f\left(e_{n-1}\right)\right] \bmod (3 n-1)=n+3, \\
f^{*}\left(v_{i}\right) & =\left[f\left(e_{i}\right)+f\left(e_{i-1}\right)+f\left(e_{i+n-1}\right)\right] \bmod (3 n-1)=2 i, \quad i=2,3, \ldots, \frac{n-1}{2}, \\
f^{*}\left(v_{(n+1) / 2}\right) & =\left[f\left(e_{(n+1) / 2}\right)+f\left(e_{(n-1) / 2}\right)\right] \bmod (3 n-1)=2 n, \\
f^{*}\left(v_{(n+3) / 2}\right) & =\left[f\left(e_{(n+3) / 2}\right)+f\left(e_{(n+1) / 2}\right) f\left(e_{3(n-1) / 2}\right)\right] \bmod (3 n-1)=2 n+2, \\
f^{*}\left(v_{i}\right) & =\left[f\left(e_{i}\right)+f\left(e_{i-1}\right)+f\left(e_{2 n-i}\right)\right] \bmod (3 n-1)=n-2 i+5, \quad i=\frac{n+5}{2}, \ldots, n-1 .
\end{aligned}
$$

Clearly all the label of the vertices are even and distinct, changed inside the set $\{0,2,4, \ldots, 2 q+2 r-2\}=\{0,2, \ldots, 3 n$ $-1\}$. Hence the tortoise $T_{n}$ has a 2 - edge even labeling.

Illustration. A 2-edge even labeling of the tortoise graph $T_{11}$ is shown in Figure 16.

\section{The $r$-Edge Even Graceful Labeling of Some Cycle-Related Graphs}

3.1. Ther-Edge Even Graceful Labeling of the Even Cycle Graph $C_{m}$. The cycle graph $C_{m}$ has an edge even graceful labeling only when $m$ is an odd number [8], so we will study the case when $m$ is an even number, i.e., $m=2 n$. 


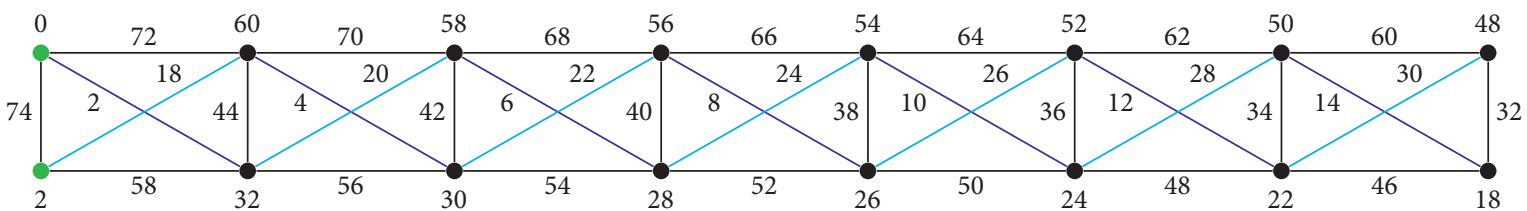

FIGURE 14: A 2-edge even graceful for the diagonal ladder $\mathrm{DL}_{8}$.

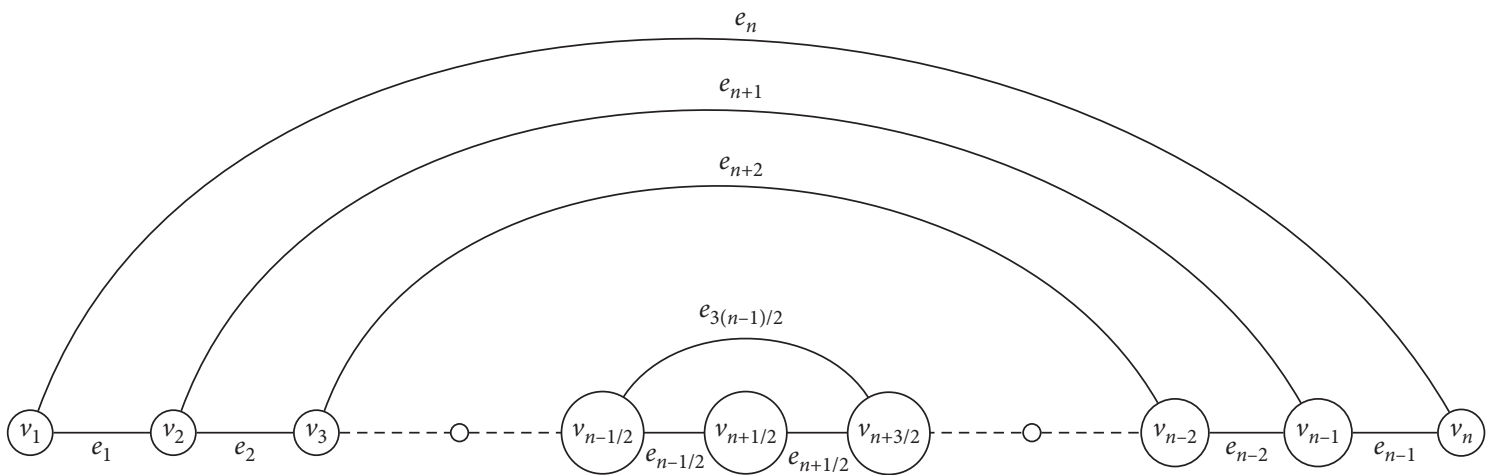

FIgURE 15: The tortoise graph $T_{n}$ with ordinary labeling.

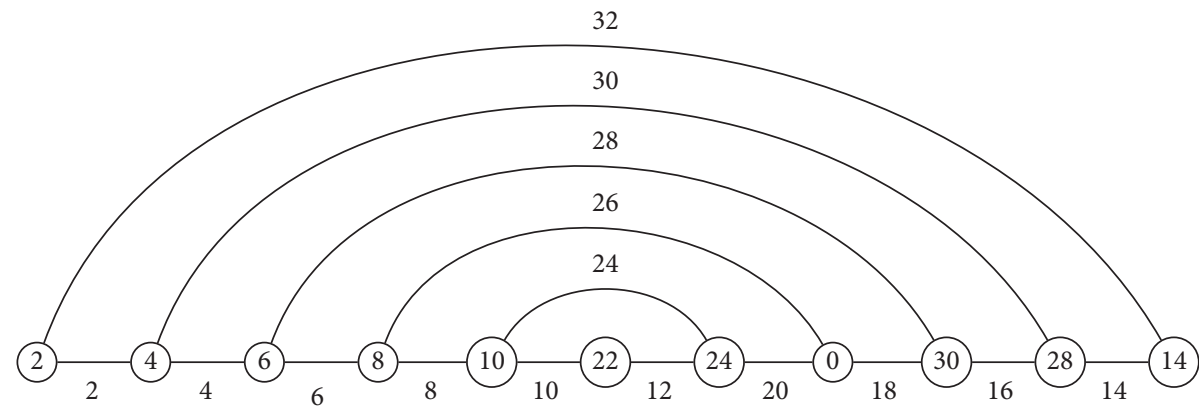

Figure 16: A 2-edge even graceful labeling for the tortoise graph $T_{11}$.

Theorem 9. The cycle graph $C_{2 n}$ has 2-edge even graceful labeling. If $n$ is even, the label is strong.

Proof. In the cycle graph $C_{2 n}, p=q=2 n$. If we assume that $r=2$, then $2 q+2 r-2=4 n+2$. We will try to define an injective mapping $f: E(G) \longrightarrow\{2,4, \ldots, 4 n+2\}$ such that $f^{*}(v)=\left(\sum_{u \in V(G)} f(u v)\right) \bmod (4 n+2)$ is an injective. Now there are two cases.

Case (1). When $n$ is odd. Let the cyclic graph $C_{2 n}$ be given as shown in Figure 17(a). The cyclic edges
$E\left(C_{2 n}\right)=\left\{e_{1}, e_{2}, \ldots, e_{n}, e_{n+1}, e_{n+2}, \ldots, e_{2 n-1}, e_{2 n}\right\}$ will be labeled as $\left\{e_{1}, e_{2}, \ldots, e_{n}, a_{1}, a_{2}, \ldots, a_{n-1}, a_{n}\right\}$, where $\left\{a_{i}=e_{n+i}, i=1, \ldots, n\right\}$ such that $a_{i}$ is put opposite to $e_{i}$. We define the labeling function $f: E(G) \longrightarrow\{2,4, \ldots, 4 n+2\}$ as follows:

$$
\begin{aligned}
& f\left(e_{i}\right)=2 i, \quad i=1,2, \ldots, n, \\
& f\left(a_{i}\right)=4 n+4-2 i, \quad i=1,2, \ldots, n
\end{aligned}
$$

we see that 


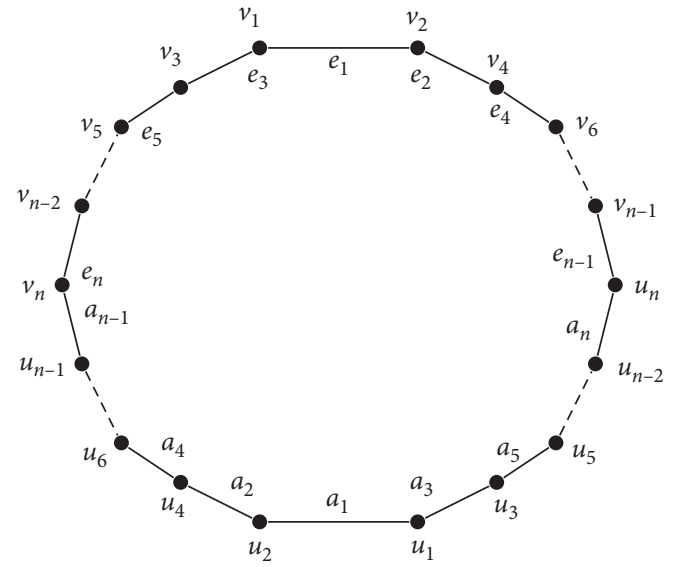

(a)

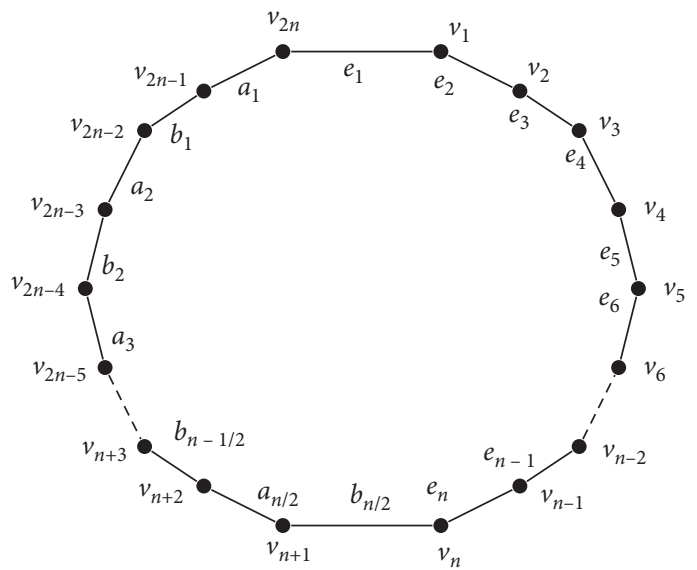

(b)

FIgURE 17: (a) $C_{2 n}$ with ordinary labeling when $n$ is odd. (b) $C_{2 n}$ with ordinary labeling when $n$ is even.

$$
\begin{aligned}
& f^{*}\left(v_{2}\right)=\left[f\left(e_{2}\right)+f\left(e_{1}\right)\right] \bmod (4 n+2)=6, \\
& f^{*}\left(v_{n}\right)=\left[f\left(e_{n}\right)+f\left(a_{n-1}\right)\right] \bmod (4 n+2)=(4 n+6) \bmod (4 n+2)=4, \\
& f^{*}\left(v_{i}\right)=\left\{\begin{array}{l}
\left\{f\left(e_{i}\right)+f\left(e_{i-2}\right)\right\} \bmod (4 n+2)=4 i-4, \quad \text { if } i=4,6, \ldots, n-1, \\
\left\{f\left(e_{i}\right)+f\left(e_{i+2}\right)\right\} \bmod (4 n+2)=4 i+4, \quad \text { if } i=1,3, \ldots, n-2,
\end{array}\right. \\
& f^{*}\left(u_{1}\right)=\left[f\left(a_{3}\right)+f\left(a_{1}\right)\right] \bmod (4 n+2)=f\left(a_{3}\right)=4 n-2, \\
& f^{*}\left(u_{2}\right)=\left[f\left(a_{2}\right)+f\left(a_{1}\right)\right] \bmod (4 n+2)=f\left(a_{2}\right)=4 n, \\
& f^{*}\left(u_{n}\right)=\left[f\left(e_{n-1}\right)+f\left(a_{n}\right)\right] \bmod (4 n+2)=0, \\
& f^{*}\left(u_{i}\right)=\left\{\begin{array}{l}
\left\{f\left(a_{i}\right)+f\left(a_{i-2}\right)\right\} \bmod (4 n+2)=4 n+10-4 i, \quad \text { if } i=4,6, \ldots, n-1, \\
\left\{f\left(a_{i}\right)+f\left(a_{i+2}\right)\right\} \bmod (4 n+2)=4 n+2-4 i, \quad \text { if } i=3,5, \ldots, n-2 .
\end{array}\right.
\end{aligned}
$$

Hence, the labels of the vertices $v_{1}, v_{3}, v_{5}, \ldots, v_{n-2}$ are $8,16,24, \ldots, 4 n-4$, respectively, and the labels of the vertices $v_{4}, v_{6}, v_{8}, \ldots, v_{n-1}$ are $12,20,28, \ldots, 4 n-8$, respectively. The labels of the vertices $u_{3}, u_{5}, \ldots, u_{n-2}$ are $4 n-10,4 n-18, \ldots, 10$ and the labels of the vertices $u_{4}, u_{6}, \ldots, v_{n-1}$ will be $4 n-6,4 n-14, \ldots, 14$, respectively. Therefore, the vertex labels are even and distinct. So, the graph has 2-edge even graceful labeling. Case (2). When $n$ is even. Let $C_{2 n}$ be given as shown in Figure $17(\mathrm{~b})$, and we define the labeling function $f: E(G) \longrightarrow\{2,4, \ldots, 4 n+2\}$ as follows:

$$
\begin{aligned}
& f\left(e_{i}\right)=2 i, \quad i=1,2, \ldots, n, \\
& f\left(a_{i}\right)=(4 n+2)-f\left(e_{2 i}\right)=4 n+2-4 i, \quad i=1,2, \ldots, \frac{n}{2}, \\
& f\left(b_{i}\right)=(4 n+2)-f\left(e_{2 i-1}\right)=4 n+4-4 i, \quad i=1,2, \ldots, \frac{n}{2} .
\end{aligned}
$$

Thus, the vertex labels are

$$
\begin{aligned}
f^{*}\left(v_{i}\right) & =\left[f\left(e_{i}\right)+f\left(e_{i+1}\right)\right] \bmod (4 n+2)=4 i+2 ; \quad i=1,2, \ldots, n-1, \\
f^{*}\left(v_{n}\right) & =\left(f\left(e_{n}\right)+f\left(b_{(n / 2)}\right)\right) \bmod (4 n+2)=(4 n+4) \bmod (4 n+2)=2, \\
f^{*}\left(v_{2 n}\right) & =\left[f\left(e_{1}\right)+f\left(a_{1}\right)\right] \bmod (4 n+2)=4 n, \\
f^{*}\left(v_{2 n-i}\right) & = \begin{cases}\left\{f\left(a_{((i+1) / 2)}\right)+f\left(b_{((i+1) / 2)}\right)\right\} \bmod (4 n+2)=4 n-4 i, & \text { if } i=1,3,5, \ldots, n+1, \\
\left\{f\left(a_{(i / 2)+1}\right)+f\left(b_{(i / 2)}\right)\right\} \bmod (4 n+2)=4 n-4 i, & \text { if } i=2,4,6, \ldots, n+2 .\end{cases}
\end{aligned}
$$


Hence, the labels of the vertices $v_{1}, v_{2}, v_{3}, v_{4}, \ldots, v_{n-1}$ will be $6,10,14,18, \ldots, 4 n-2$, respectively, and the labels of the vertices $v_{n+1}, v_{n+2}, v_{n+3}, v_{n+4}, \ldots, v_{2 n-1}$ will be $4,8,12,16$, $\ldots, 4 n-4$. Therefore the vertex labels are even and distinct and changed inside the set $\{2 r-2,2 r, \ldots, 2 q+2 r-2\}=$ $\{2,-4, \ldots, 4 n+2\}$. So, the graph $C_{2 . n}$ has strong 2-edge even graceful labeling when $n$ is even.

Illustration. The graphs $C_{18}$ and $C_{16}$ labeled according to Theorem 9 are presented in Figure 18.

3.2. The r-Edge Even Graceful Labeling of the Crown $R_{n}$ and $C_{n} \odot \overline{K_{2 m-1}}$. A crown $R_{n}$ is formed by adding $n$ more pendent vertices $\left\{u_{1}, u_{2}, u_{3}, \ldots, u_{n}\right\}$ and $n$ more edges $\left\{\left(v_{i} u_{i}\right), i=1,2, \ldots, n\right\}$ for $n \geq 3$ to the $n$ vertices $\left\{v_{1}, v_{2}, v_{3}, \ldots, v_{n}\right\}$ of a cycle $C_{n}$.

Proposition 1. The crown graph $R_{n}$ has 2-edge even graceful labeling.

Proof. The crown graph $R_{n}$ has $p=2 n$ vertices and $q=2 n$ edges. Consider the crown graph $R_{n}$ shown in Figure 19, where $a_{i}=\left(v_{i} u_{i}\right)$ and $e_{i}=\left(v_{i} v_{i+1}\right), 1 \leq i \leq n$.

We can define the labeling $f: E\left(R_{n}\right) \longrightarrow\{2,4, \ldots, 4 n+$ $2\}$ as follows:

$$
\begin{aligned}
& f\left(e_{i}\right)=2 i, \quad i=1,2, \ldots, n, \\
& f\left(a_{i}\right)=4 n-2 i+4, \quad i=1,2, \ldots, n .
\end{aligned}
$$

Now, the induced labels of the vertices are

$$
\begin{aligned}
f^{*}\left(v_{1}\right) & =\left[f\left(e_{1}\right)+f\left(e_{n}\right)+f\left(a_{1}\right)\right] \bmod (4 n+2) \\
& =[6 n+4] \bmod (4 n+2)=2 n+2, \\
f^{*}\left(v_{i}\right) & =\left[f\left(e_{i}\right)+f\left(e_{i-1}\right)+f\left(a_{i}\right)\right] \bmod (4 n+2) \\
& =[4 n+2+2 i] \bmod (4 n+2)=2 i, \quad i=2,3, \ldots, n .
\end{aligned}
$$

Also, the vertices $u_{i}$ take the labels of the pendant edges which are $\{0,4 n, 4 n-2, \ldots, 2 n+4\}$, so overall all the vertex labels are even and there is no repetition. Thus, the crown graph $R_{n}$ has 2 -edge even graceful labeling.

The generalization of the previous result is presented in the following theory.

Theorem 10. The graph $C_{n} \odot \overline{K_{2 m-1}}$ has 2-edge even graceful labeling.

Proof. In the graph $C_{n} \odot \overline{K_{2 m-1}}$, the cardinality of the vertex set and the edge set is $p=4 m n$ and $q=4 m n$, respectively. Let the vertex and edge symbols be given as in Figure 20 .

Let $r=2$, and we define the labeling map $f: E\left(C_{n} \odot \overline{K_{2 m-1}}\right) \longrightarrow\{2,4, \ldots, 4 m n+2\}$ as follows:

$$
\begin{aligned}
f\left(E_{i}\right) & =2 i, \quad \text { for } i=1,2, \ldots, n, \\
f\left(e_{i}\right) & =4 m n+2(1-i), \quad \text { for } i=1,2, \ldots, n, \\
f\left(A_{i j}\right) & =2 n+4(i-1)+2 j, \quad \text { for } j=1,2, \ldots, m-1, \\
f\left(B_{i j}\right) & =4 m n-2 n-4 i-2 j+6, \quad \text { for } j=1,2, \ldots, m-1 .
\end{aligned}
$$

We realize the following:

$$
\begin{array}{rlrl}
{\left[f\left(A_{i j}\right)+f\left(B_{i j}\right)\right] \bmod (4 m n+2)} & \equiv 0 \bmod (4 m n+2), & & \text { for } j=1,2, \ldots, m-1, \\
{\left[f\left(E_{i}\right)+f\left(e_{i}\right)\right] \bmod (4 m n+2) \equiv 0 \bmod (4 m n+2),} & \text { for } i=1,2,3, \ldots, n .
\end{array}
$$

Then, we have

$$
\begin{aligned}
f^{*}\left(v_{i}\right) & =\left[\sum_{j=1}^{m-1} f\left(A_{i j}\right)+\sum_{j=1}^{m-1} f\left(B_{i j}\right)+f\left(E_{i}\right)+f\left(E_{i-1}\right)+f\left(e_{i}\right)\right] \bmod (4 m n+2), \quad i=2,3, \ldots, n \\
& =f\left(E_{i-1}\right) \bmod (4 m n+2)=2(i-1), \quad i=2,3, \ldots, n .
\end{aligned}
$$




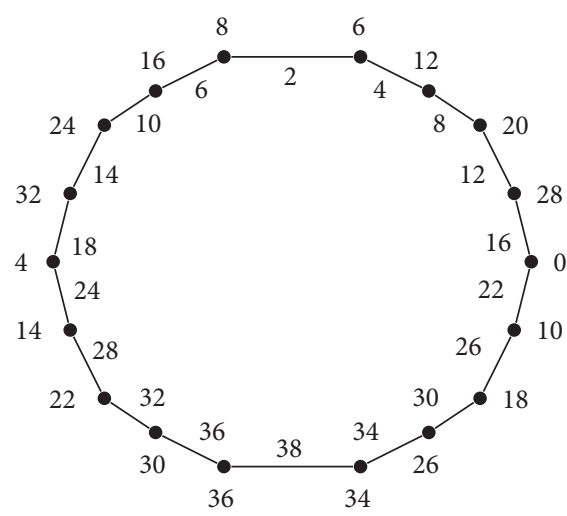

(a)

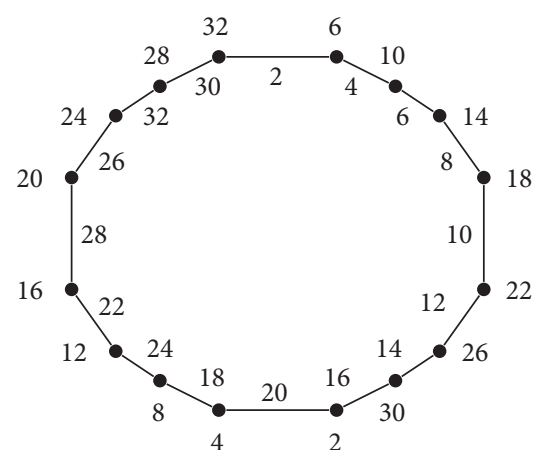

(b)

FIgURE 18: (a) A 2-edge even graceful labeling of $C_{18}=C_{2.9}$. (b) A strong 2-edge even graceful labeling of $C_{16}=C_{2.8}$.

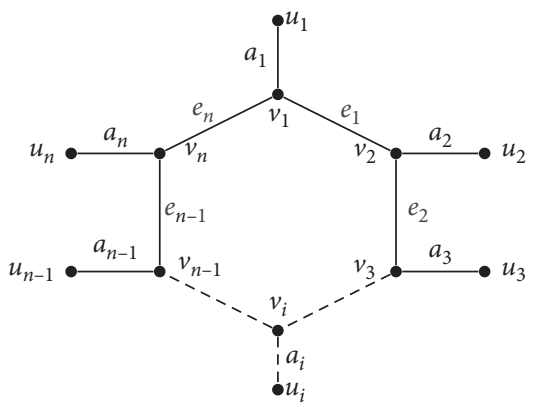

FIgURE 19: The crown graph $R_{n}$ with ordinary labeling.

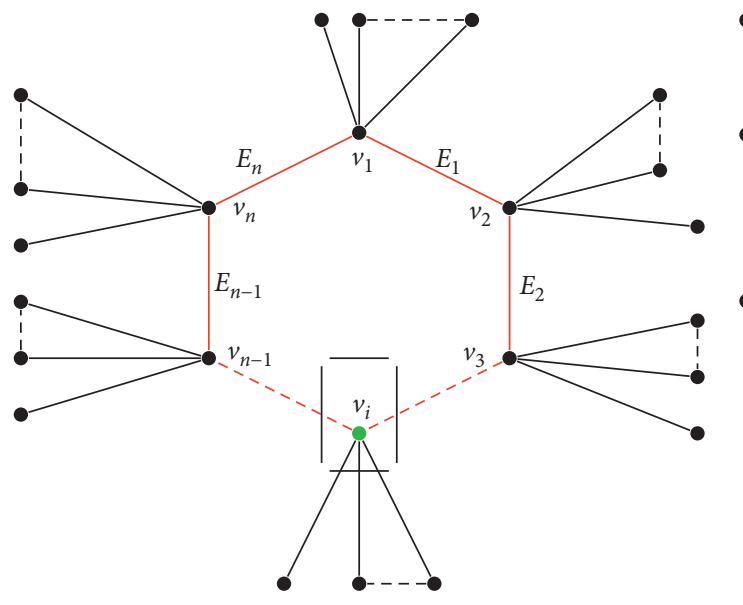

(a)

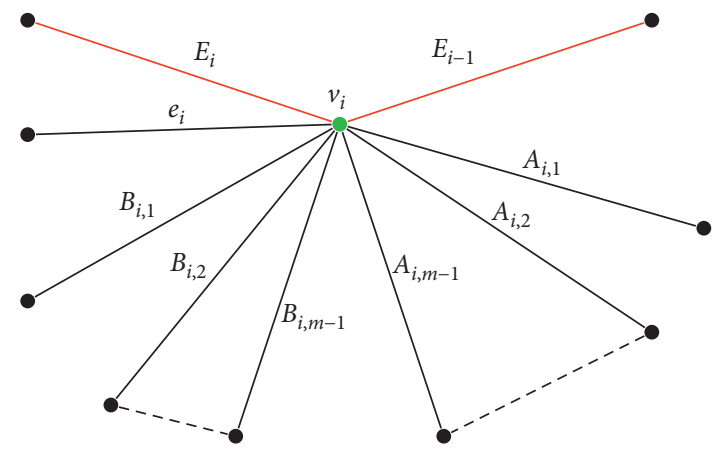

(b)

FIGURE 20: $C_{n} \odot \overline{K_{2 m-1}}$ with ordinary labeling.

Similarly, $f^{*}\left(v_{1}\right)=f\left(E_{n}\right)=2 n$.

Hence, the labels of the vertices $v_{1}, v_{2}, \ldots, v_{n}$ take the label of the edges of the cycles and each of the pendant vertices takes the label of its edge, so they are all even and different numbers.

Illustration. In Figure 21, we present 2-edge even graceful labeling of the crown $R_{9}$ and the graph $C_{6} \odot \overline{K_{5}}$.
3.3. The r-Edge Even Graceful Labeling of the Helm Graph $H_{n}$. The helm $H_{n}$ is formed from the wheel graph $W_{n}=\left\{v_{0}, v_{1}, v_{2}, v_{3}, \ldots, v_{n}\right\}$ where $v_{0}$ is the center vertex by adding $n$ more pendent vertices $\left\{u_{1}, u_{2}, u_{3}, \ldots, u_{n}\right\}$ and $n$ more edges $\left\{\left(v_{i} u_{i}\right), i=1,2, \ldots, n\right\}$.

Theorem 11. For $n \geq 3$, the helm graph $H_{n}$ has 2-edge even graceful labeling. 


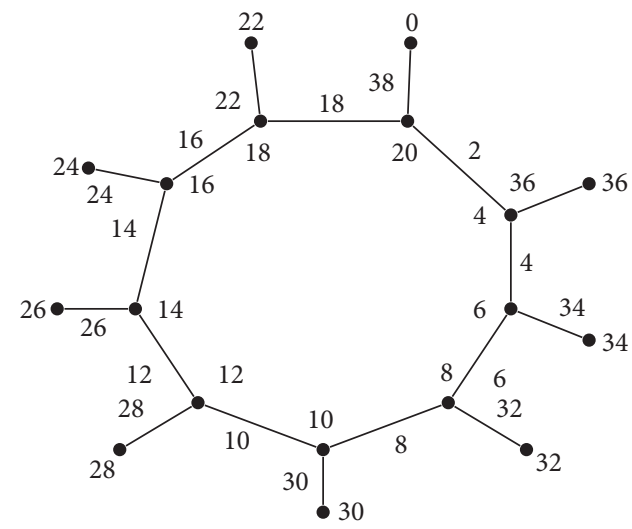

(a)

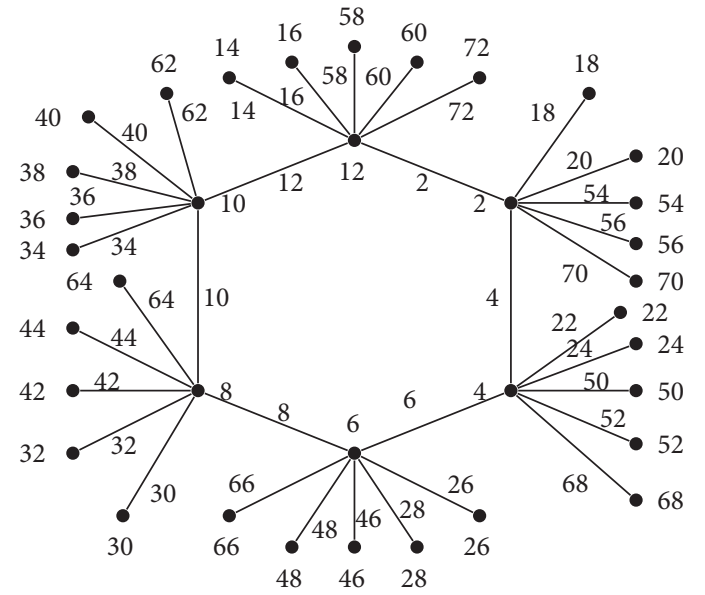

(b)

FiguRE 21: (a) 2-edge even graceful labeling of the crown $R_{9}$. (b) 2-edge even graceful labeling of $C_{6} \odot \overline{K_{5}}$.

Proof. The helm graph $H_{n}$ has $p=2 n+1$ vertices and $q=$ $3 n$ edges and $K=\max (p, q)=3 n$. Let the helm graph $H_{n}$ be given as indicated in Figure 22. We assume that $r=2$; then, $2 q+2 r-2=6 n+2$.

To find the labeling function $f: E\left(H_{n}\right) \longrightarrow\{2,4$, $\ldots, 6 n+2\}$, we have two cases.

Case (1). When $n$ is even, we define the labeling function $f: E\left(H_{n}\right) \longrightarrow\{2,4, \ldots, 6 n+2\}$ as follows:

$$
\begin{aligned}
& f\left(e_{i}\right)=\left\{\begin{array}{l}
3 n+2 i, \quad \text { if } i=1,2, \ldots, \frac{n}{2}, \\
6 n+2, \quad \text { if } i=\frac{n}{2}+1, \\
3 n+2 i-2, \quad \text { if } i=\frac{n}{2}+2, \ldots, n,
\end{array}\right. \\
& f\left(v_{0} v_{i}\right)=\left\{\begin{array}{l}
2 i, \quad \text { if } i=1,2, \ldots, \frac{n}{2}, \\
4 n+2 i, \quad \text { if } i=\frac{n}{2}+1, \frac{n}{2}+2, \ldots, n,
\end{array}\right. \\
& f\left(v_{i} u_{i}\right)=\left\{\begin{array}{l}
n+2, \quad \text { if } i=1, \\
3 n+4-2 i, \quad \text { if } i=2,3, \ldots, n .
\end{array}\right.
\end{aligned}
$$

In this labeling, we notice that

(i) $\left[f\left(v_{0} v_{i}\right)+f\left(v_{0} v_{n-i+1}\right)\right] \quad \bmod (6 n+2) \equiv 0 \bmod$ $(6 n+2)$, for $i=1,2, \ldots,(n / 2)$.

(ii) $\left[f\left(v_{i} u_{i}\right)+f\left(e_{i-1}\right)\right] \bmod (6 n+2) \equiv 0 \bmod (6 n+$ 2), for $i=2, \ldots,(n / 2)$.

(iii) $\left[f\left(v_{i} u_{i}\right)+f\left(e_{i}\right)\right] \bmod (6 n+2) \equiv 0 \bmod (6 n+2)$, for $i=(n / 2)+2, \ldots, n$.

In view of the above labeling pattern, the induced vertex labels are

$$
\begin{aligned}
f^{*}\left(v_{0}\right) & =\left[\sum_{i=1}^{n} f\left(v_{0} v_{i}\right)\right] \bmod (6 n+2)=0, \\
f^{*}\left(v_{1}\right) & =\left[f\left(e_{1}\right)+f\left(e_{n}\right)+f\left(v_{0} v_{1}\right)+f\left(v_{1} u_{1}\right)\right] \bmod (6 n+2)=3 n+2, \\
f^{*}\left(v_{(n / 2)+1}\right) & =\left[f\left(e_{(n / 2)+1}\right)+f\left(e_{(n / 2)}\right)+f\left(v_{0} v_{(n / 2)+1}\right)+f\left(v_{(n / 2)+1} u_{(n / 2)+1}\right)\right] \bmod (6 n+2)=5 n+2, \\
f^{*}\left(v_{(n / 2)+2}\right) & =\left[f\left(e_{(n / 2)+2}\right)+f\left(e_{(n / 2)+1}\right)+f\left(v_{0} v_{(n / 2)+2}\right)+f\left(v_{(n / 2)+2} u_{(n / 2)+2}\right)\right] \bmod (6 n+2)=5 n+4 .
\end{aligned}
$$




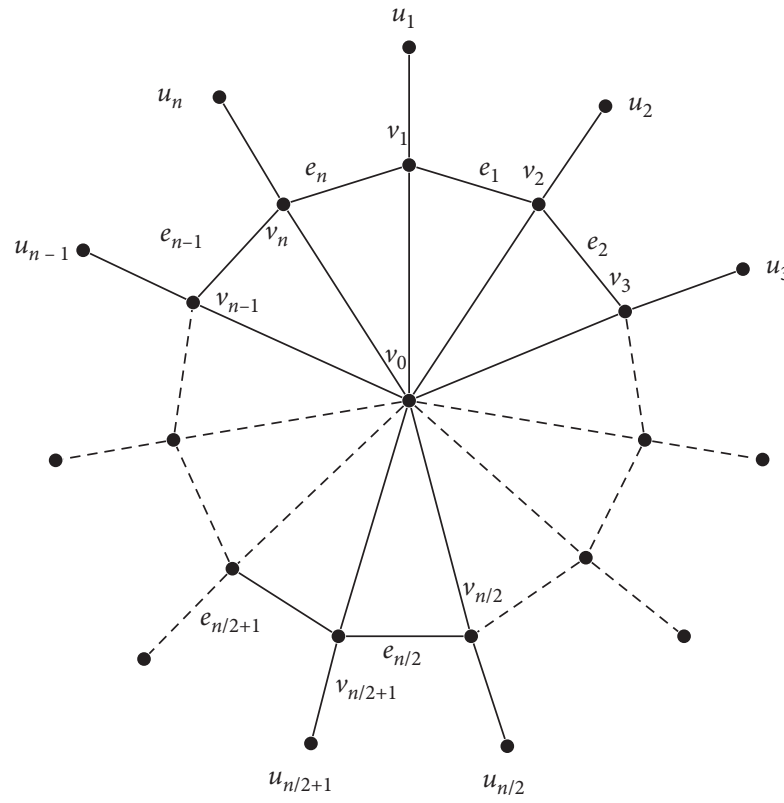

(a)

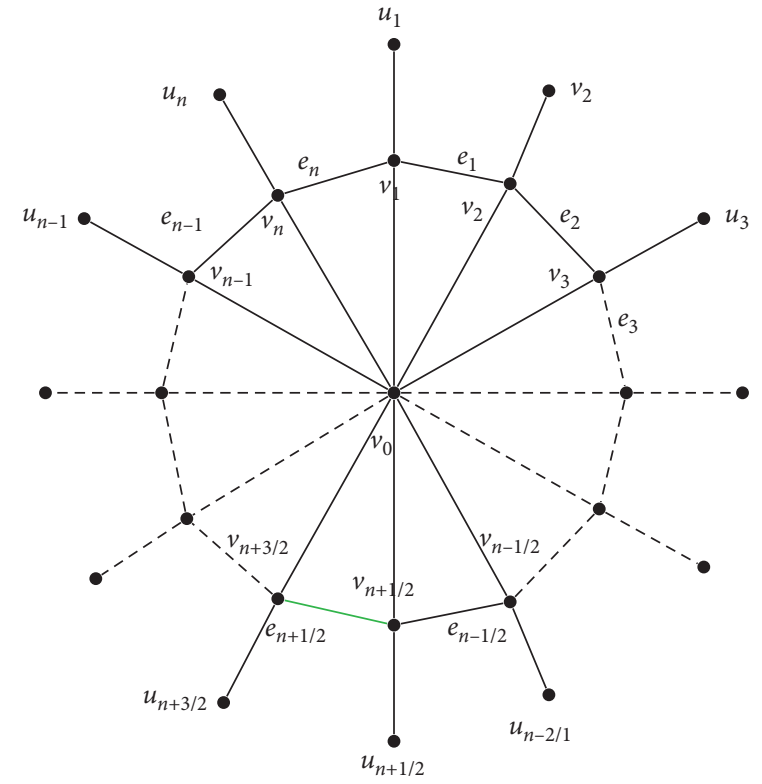

(b)

Figure 22: (a) The graph $H_{n}$ when $n$ is even. (b) The graph $H_{n}$ when $n$ is odd.

Since $f^{*}\left(v_{i}\right)=\left[f\left(e_{i}\right)+f\left(e_{i-1}\right)+f\left(v_{0} v_{i}\right)+f\left(v_{i} u_{i}\right)\right]$ $\bmod (6 n+2)$,

$f^{*}\left(v_{i}\right)= \begin{cases}(3 n+4 i) \bmod (6 n+2), & \text { if } i=2,3, \ldots, \frac{n}{2}, \\ (n-6+4 i) \bmod (6 n+2), & \text { if } i=\frac{n}{2}+3, \ldots, n .\end{cases}$

Hence, the labels of the vertices $v_{2}, v_{3}, \ldots, v_{(n / 2)-1}, v_{(n / 2)}$ will be $3 n+8,3 n+12, \ldots, 5 n-4,5 n$, respectively, and the labels of the vertices $v_{(n / 2)+3}, v_{(n / 2)+4}, \ldots, v_{n-1}, v_{n}$ will be $3 n+6,3 n+10, \ldots, 5 n-10,5 n-6$, respectively, which are all even and distinct numbers.

Case (2). When $n$ is odd, by considering the helm graph $H_{n}$ shown in Figure 22(b), we can define the labeling $f: E\left(H_{n}\right) \longrightarrow\{2,4, \ldots, 6 n+2\}$ as follows:

$$
\begin{aligned}
& f\left(e_{i}\right)= \begin{cases}3 n+2 i-1, & \text { if } i=1,2, \ldots, \frac{n-1}{2}, \\
3 n+2 i+1, & \text { if } i=\frac{n+1}{2}, \ldots, n,\end{cases} \\
& f\left(v_{0} v_{i}\right)=\left\{\begin{array}{l}
2 i, \quad \text { if } i=1,2, \ldots, \frac{n-1}{2}, \\
4 n+2 i+2, \quad \text { if } i=\frac{n+1}{2}, \ldots, n,
\end{array}\right. \\
& f\left(v_{i} u_{i}\right)=\left\{\begin{array}{l}
n+1, \quad \text { if } i=1, \\
3 n+3-2 i,
\end{array} \quad \text { if } i=2,3, \ldots, n .\right.
\end{aligned}
$$

In this labeling, we notice that

(i) $\left[f\left(v_{0} v_{i}\right)+f\left(v_{0} v_{n-i}\right)\right] \bmod (6 n+2) \equiv 0 \bmod (6 n+$ 2), for $i=1,2, \ldots,(n-1) / 2$.

(ii) $\left[f\left(v_{i} u_{i}\right)+f\left(e_{i}\right)\right] \bmod (6 n+2) \equiv 0 \bmod (6 n+2)$, for $i=2, \ldots,(n-1) / 2$.

(iii) $\left[f\left(v_{i} u_{i}\right)+f\left(e_{i-1}\right)\right] \bmod (6 n+2) \equiv 0 \bmod (6 n+2)$, for $i=(n+3) / 2, \ldots, n$.

Considering the vertex labels, the induced vertex labels are

$$
\begin{aligned}
f^{*}\left(v_{0}\right)= & {\left[\sum_{i=1}^{n} f\left(v_{0} v_{i}\right)\right] \bmod (6 n+2)=0, } \\
f^{*}\left(v_{1}\right)= & {\left[f\left(e_{1}\right)+f\left(e_{n}\right)+f\left(v_{0} v_{1}\right)+f\left(v_{1} u_{1}\right)\right] } \\
& \bmod (6 n+2)=3 n+3, \\
f^{*}\left(v_{(n+1) / 2}\right)= & {\left[f\left(e_{(n+1) / 2}\right)+f\left(e_{(n-1) / 2}\right)+f\left(v_{0} v_{(n+1) / 2}\right)\right.} \\
& \left.+f\left(v_{(n+1) / 2} u_{(n+1) / 2}\right)\right] \bmod (6 n+2)=3 n+1 .
\end{aligned}
$$

Since $\quad f^{*}\left(v_{i}\right)=\left[f\left(e_{i}\right)+f\left(e_{i-1}\right)+f\left(v_{0} v_{i}\right)+f\left(v_{i} u_{i}\right)\right]$ $\bmod (6 n+2)$,

$$
f^{*}\left(v_{i}\right)= \begin{cases}(3 n+4 i-3) \bmod (6 n+2), & \text { if } i=2,3, \ldots, \frac{n-1}{2}, \\ (n+1+4 i) \bmod (6 n+2), & \text { if } i=\frac{n+3}{2}, \ldots, n .\end{cases}
$$

Hence, the labels of the vertices $v_{2}, v_{3}, \ldots, v_{(n-3) / 2}$, $v_{(n-1) / 2}$ are $3 n+5,3 n+9, \ldots, 5 n-9,5 n-5$, respectively, and the labels of the vertices $v_{(n+3) / 2}, v_{(n+5) / 2}, \ldots, v_{n-1}, v_{n}$ are 
$3 n+7,3 n+11, \ldots, 5 n-3,5 n+1$, respectively, which are all even and distinct numbers. Thus, the helm graph $H_{n}$ has 2-edge even graceful labeling.

Illustration. In Figure 23, we present a 2-edge even graceful labeling of $H_{11}$ and $H_{12}$.

3.4. The r-Edge Even Graceful Labeling of the Sunflower Graph $s f_{n}$. The sunflower graph, $\mathrm{sf}_{n}$, is defined as a graph obtained by starting with an n-cycle $C_{n}$ with consecutive vertices $\left\{v_{1}, v_{2}, \ldots, v_{n}\right\}$ and creating new vertices $\left\{u_{1}, u_{2}, \ldots, u_{n}\right\}$, with $u_{i}$ connected to $v_{i}$ and $v_{i+1}$, so

$$
E\left(\mathrm{sf}_{n}\right)=\left\{a_{i}=v_{i} u_{i}, b_{i}=u_{i} v_{i+1}, c_{i}=v_{i} v_{i+1}\right\} .
$$

Theorem 12. The sunflower graph, $s f_{n}$, has 2-edge even graceful labeling.

Proof. The graph $\mathrm{sf}_{n}$ has $p=2 n$ vertices and $q=3 n$ edges and $K=\max (p, q)=3 n$ (see Figure 24). Assume that $r=2$; then, $2 q+2 r-2=6 n+2$, and we consider two cases.
Case (1). When $n$ is even. The labeling $f: E\left(\mathrm{sf}_{n}\right) \longrightarrow\{2,4, \ldots, 6 n+2\}$ can be defined as follows:

$$
\begin{aligned}
& f\left(a_{i}\right)=2 i, \quad \text { for } i=1,2,3, \ldots, n, \\
& f\left(b_{i}\right)=6 n+4-4 i, \quad \text { for } i=1,2,3, \ldots, n, \\
& f\left(c_{i}\right)=\left\{\begin{array}{l}
2 n+2 i, \quad \text { if } i=1,3, \ldots, n-1, \\
6 n+2-2 i, \quad \text { if } i=2,4, \ldots, n .
\end{array}\right.
\end{aligned}
$$

The induced vertex labels are

$$
\begin{aligned}
f^{*}\left(u_{i}\right) & =\left[f\left(a_{i}\right)+f\left(b_{i}\right)\right] \bmod (6 n+2) \\
& =(6 n+4-2 i) \bmod (6 n+2), \quad \text { for } i=1,2, \ldots, n, \\
f^{*}\left(v_{1}\right) & =\left[f\left(a_{1}\right)+f\left(b_{n}\right)+f\left(c_{n}\right)+f\left(c_{1}\right)\right] \bmod (6 n+2) \\
& =2 n+8 .
\end{aligned}
$$

Since $\quad f^{*}\left(v_{i}\right)=\left[f\left(a_{i}\right)+f\left(b_{i-1}\right)+f\left(c_{i}\right)+f\left(c_{i-1}\right)\right]$ $\bmod (6 n+2)$

$$
f^{*}\left(v_{i}\right)= \begin{cases}(2 n+8-2 i) \bmod (6 n+2), & \text { if } i=3,5, \ldots, n-1, \\ (2 n+4-2 i) \bmod (6 n+2), & \text { if } i=2,4, \ldots, n\end{cases}
$$

Hence, the labels of the vertices $u_{1}, u_{2}, u_{3}, \ldots, u_{n-1}, u_{n}$ are $0,6 n, 6 n-2, \ldots, 4 n+6,4 n+4$, respectively, and the labels of the vertices $v_{3}, v_{5}, \ldots, v_{n-3}, v_{n-1}$ will be $2 n+2,2 n-2, \ldots, 14,10$, respectively. Also, the labels of the vertices $v_{2}, v_{4}, \ldots, v_{n-2}, v_{n}$ will be $2 n, 2 n-4, \ldots, 8,4$, respectively, which are all even and distinct numbers.

Case (2). When $n$ is odd, we define the labeling $f: E\left(\mathrm{sf}_{n}\right) \longrightarrow\{2,4, \ldots, 6 n+2\}$ as follows:

$$
\begin{aligned}
& f\left(a_{i}\right)=2 i, \quad \text { for } i=1,2,3, \ldots, n, \\
& f\left(b_{i}\right)=6 n+4-4 i, \quad \text { for } i=1,2,3, \ldots, n, \\
& f\left(c_{i}\right)=\left\{\begin{array}{l}
2 n+2 i, \quad \text { if } i=1,3, \ldots, n, \\
6 n+2-2 i, \quad \text { if } i=2,4, \ldots, n-1 .
\end{array}\right.
\end{aligned}
$$

The induced vertex labels are

$$
\begin{aligned}
f^{*}\left(u_{i}\right) & =\left[f\left(a_{i}\right)+f\left(b_{i}\right)\right] \bmod (6 n+2) \\
& =(6 n+4-2 i) \bmod (6 n+2), \quad \text { for } i=1,2, \ldots, n, \\
f^{*}\left(v_{1}\right) & =\left[f\left(a_{1}\right)+f\left(b_{n}\right)+f\left(c_{n}\right)+f\left(c_{1}\right)\right] \bmod (6 n+2) \\
& =2 n+6 .
\end{aligned}
$$

Since $f^{*}\left(v_{i}\right)=\left[f\left(a_{i}\right)+f\left(b_{i-1}\right)+f\left(c_{i}\right)+f\left(c_{i-1}\right)\right] \bmod$ $(6 n+2)$,

$$
f^{*}\left(v_{i}\right)= \begin{cases}(2 n+8-2 i) \bmod (6 n+2), & \text { if } i=3,5, \ldots, n \\ (2 n+4-2 i) \bmod (6 n+2), & \text { if } i=2,4, \ldots, n-1\end{cases}
$$

Hence, the labels of the vertices $u_{1}, u_{2}, u_{3}, \ldots, u_{n-1}, u_{n}$ will be $0,6 n, 6 n-2, \ldots, 4 n+6,4 n+4$, respectively, and the labels of the vertices $v_{3}, v_{5}, \ldots, v_{n-2}, v_{n}$ will be $2 n+2,2 n-2, \ldots, 12,8$, respectively. Also, the labels of the vertices $v_{2}, v_{4}, \ldots, v_{n-3}, v_{n-1}$ will be $2 n, 2 n-4, \ldots, 10,6$, respectively, which are all even and distinct numbers. Thus, the sunflower graph, $\mathrm{sf}_{n}$, has 2-edge even graceful labeling.

Illustration. In Figure 25, we present 2-edge even graceful labeling of $\mathrm{sf}_{9}$ and $\mathrm{sf}_{10}$.

3.5. The r-Edge Even Graceful Labeling of the Sunflower Planar Graph $S F_{n}$. The sunflower planar graph, $\mathrm{SF}_{n}$, is defined as a graph obtained by starting with an n-wheel $W_{n}$ with a center vertex $v_{0}$ and consecutive vertices $v_{1}, v_{2}, \ldots, v_{n}$ and creating new vertices $u_{1}, u_{2}, \ldots, u_{n}$, with $u_{i}$ connected to $v_{i}$ and $v_{i+1}$, so $E\left(\mathrm{sf}_{n}\right)=\left\{v_{0} v_{i}, a_{i}=v_{i} u_{i}, b_{i}=u_{i} v_{i+1}, c_{i}=v_{i} v_{i+1}\right\}$.

Theorem 13. The sunflower planar graph, $\mathrm{SF}_{n}$, has 2-edge even graceful labeling.

Proof. The graph $\mathrm{SF}_{n}$ always has an odd number of vertices $p=2 n+1$ and a number of edges $q=4 n$ and 


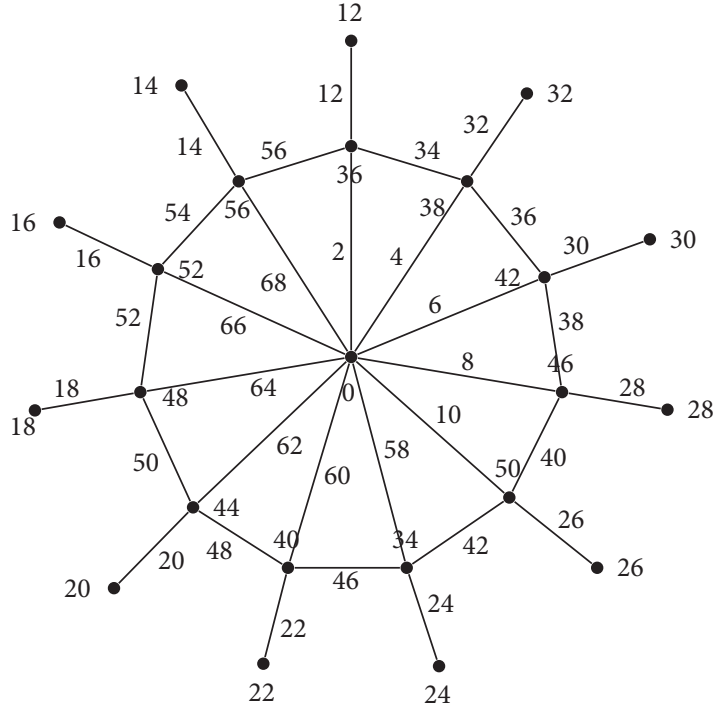

(a)

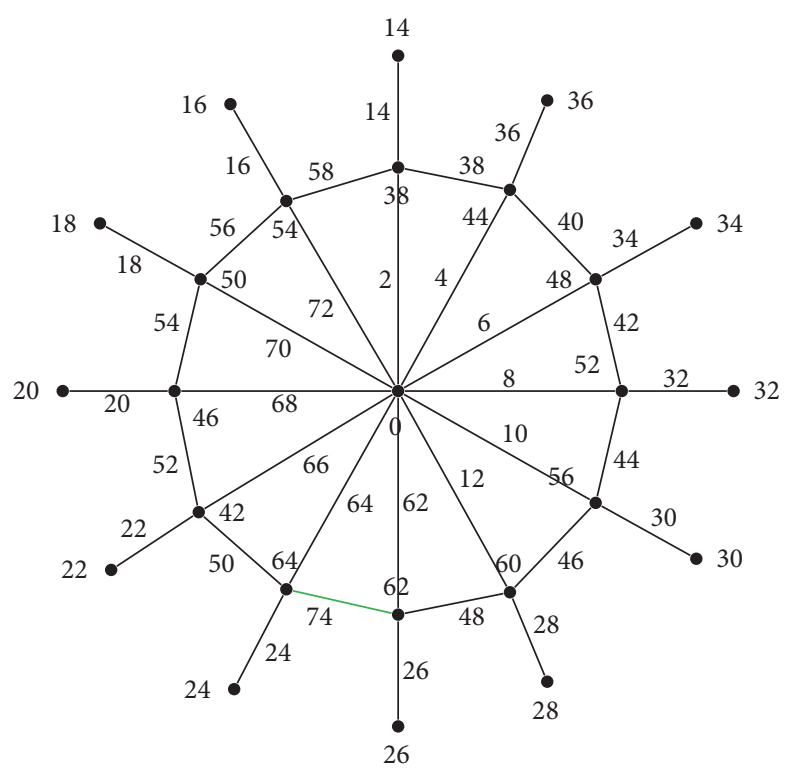

(b)

FIGURE 23: (a) 2-edge even graceful labeling of $H_{11}$. (b) 2-edge even graceful labeling of $H_{12}$.

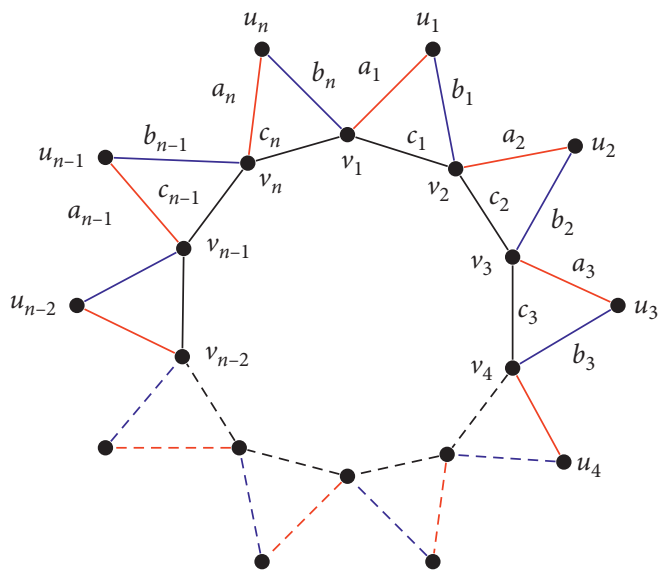

FIgURE 24: The graph $\mathrm{sf}_{n}$ with ordinary labeling.

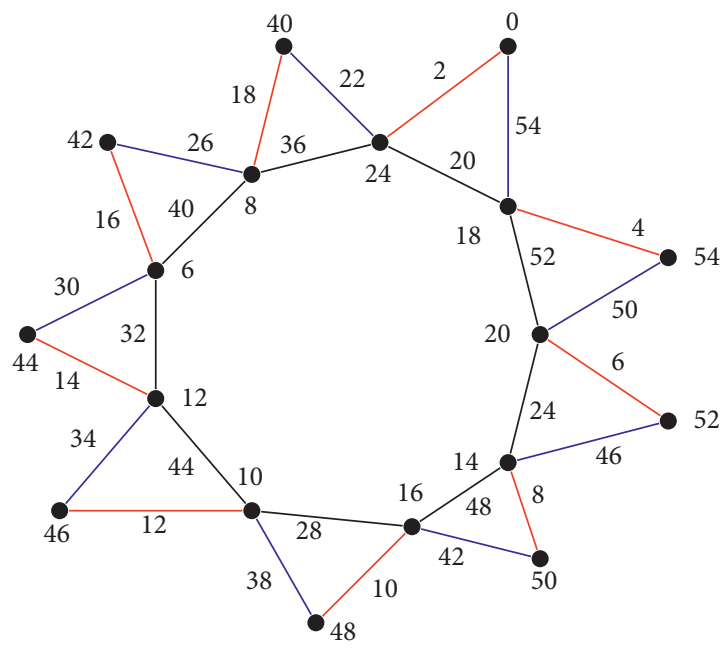

(a)

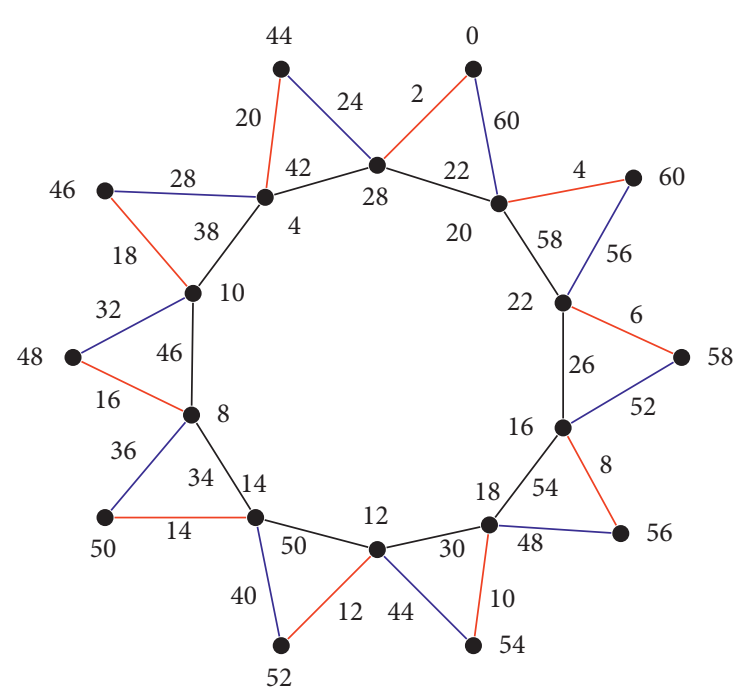

(b)

FIgURE 25: (a) A 2-edge even graceful labeling of $\mathrm{sf}_{9}$. (b) A 2-edge even graceful labeling of $\mathrm{sf}_{10}$. 
$K=\max (p, q)=4 n$. Consider the graph $\mathrm{SF}_{n}$ shown in Figure 26. Assume that $r=2$; then, $2 q+2 r-2=8 n+2$.

To find the label map $f: E\left(\mathrm{SF}_{n}\right) \longrightarrow\{2,4, \ldots, 8 n+2\}$, there are two cases.

Case (1). When $n$ is even. The labeling $f$ can be defined as follows:

$$
\begin{aligned}
f\left(a_{i}\right) & =n+2 i, \quad \forall i=1,2,3, \ldots, n, \\
f\left(b_{i}\right) & =3 n+2 i, \quad \forall i=1,2,3, \ldots, n, \\
f\left(v_{i} v_{i+1}\right) & =7 n+2-2 i, \quad \forall i=1,2,3, \ldots, n, \\
f\left(v_{0} v_{i}\right) & =\left\{\begin{array}{l}
2 i, \quad \text { if } i=1,2, \ldots, \frac{n}{2} \\
6 n+2 i, \quad \text { if } i=\frac{n}{2}+1, \frac{n}{2}+2, \ldots, n .
\end{array}\right.
\end{aligned}
$$

In this labeling, we can check that

(i) $\left[f\left(v_{0} v_{i}\right)+f\left(v_{0} v_{n-i+1}\right)\right] \bmod (8 n+2) \equiv 0 \bmod (8 n+$ $2)$, for $i=1,2, \ldots,(n / 2)$.

(ii) $\left[f\left(v_{i} v_{i+1}\right)+f\left(a_{i}\right)\right] \bmod (8 n+2) \equiv 0 \bmod (8 n+2)$, for $i=1,2, \ldots, n$.

In view of the above labeling pattern, the induced vertex labels are

$$
\begin{aligned}
f^{*}\left(v_{0}\right) & =\left[\sum_{i=1}^{n} f\left(v_{0} v_{i}\right)\right] \bmod (8 n+2)=0, \\
f^{*}\left(u_{i}\right) & =\left[f\left(a_{i}\right)+f\left(b_{i}\right)\right] \bmod (8 n+2) \\
& =4 n+4 i \bmod (8 n+2), \quad \text { for } i=1,2, \ldots, n .
\end{aligned}
$$

Since

$$
\begin{aligned}
& f^{*}\left(v_{i}\right)= {\left[f\left(a_{i}\right)+f\left(b_{i-1}\right)+f\left(v_{0} v_{i}\right)+f\left(v_{i} v_{i+1}\right)+f\left(v_{i} v_{i-1}\right)\right] \bmod (8 n+2), } \\
& f^{*}\left(v_{i}\right)=\left\{\begin{array}{l}
(2 n+2 i) \bmod (8 n+2), \quad \text { if } i=1,2,3, \ldots, \frac{n}{2}, \\
(2 i) \bmod (8 n+2), \quad \text { if } i=\frac{n}{2}+1, \frac{n}{2}+2, \ldots, n .
\end{array}\right.
\end{aligned}
$$

Hence, the labels of the vertices $u_{1}, u_{2}, u_{3}, \ldots, u_{n-1}, u_{n}$ are $4 n+4,4 n+8,4 n+12, \ldots, 8 n-4,8 n$, respectively, and the labels of the vertices $v_{1}, v_{2}, \ldots, v_{(n / 2)-1}, v_{(n / 2)}$ are $2 n+2,2 n+4, \ldots, 3 n-2,3 n$, respectively. Also, the labels of the vertices $v_{(n / 2)+1}, v_{(n / 2)+2}, \ldots, v_{n-1}, v_{n}$ will be $n, 3 n+2, \ldots, 2 n-4,2 n-2$, respectively, which are all even and distinct numbers.

Case (2). When $n$ is odd. Define the labeling $f: E\left(\mathrm{SF}_{n}\right) \longrightarrow\{2,4, \ldots, 8 n+2\}$ as follows:

$$
\begin{aligned}
f\left(a_{i}\right) & =n-1+2 i, \quad \forall i=1,2,3, \ldots, n, \\
f\left(b_{i}\right) & =3 n-1+2 i, \quad \forall i=1,2,3, \ldots, n, \\
f\left(v_{i} v_{i+1}\right) & =7 n+3-2 i, \quad \forall i=1,2,3, \ldots, n, \\
f\left(v_{0} v_{i}\right) & =\left\{\begin{array}{l}
2 i, \quad \text { if } i=1,2, \ldots, \frac{n-1}{2}, \\
6 n+2 i+2, \quad \text { if } i=\frac{n+1}{2}, \frac{n+3}{2}, \ldots, n .
\end{array}\right.
\end{aligned}
$$

We can check that

(i) $\left[f\left(v_{0} v_{i}\right)+f\left(v_{0} v_{n-i}\right)\right] \bmod (8 n+2) \equiv 0 \bmod$ $(8 n+2)$, for $i=1,2, \ldots,(n / 2)$.

(ii) $\left[f\left(v_{i} v_{i+1}\right)+f\left(a_{i}\right)\right] \bmod (8 n+2) \equiv 0 \bmod$ $(8 n+2)$, for $i=1,2, \ldots, n$.

In this labeling, the induced vertex labels are

$$
\begin{aligned}
f^{*}\left(v_{0}\right) & =\left[\sum_{i=1}^{n} f\left(v_{0} v_{i}\right)\right] \bmod (8 n+2)=0, \\
f^{*}\left(u_{i}\right) & =\left[f\left(a_{i}\right)+f\left(b_{i}\right)\right] \bmod (8 n+2)=4 n+4 i-2 \bmod (8 n+2), \quad \text { for } i=1,2, \ldots, n .
\end{aligned}
$$




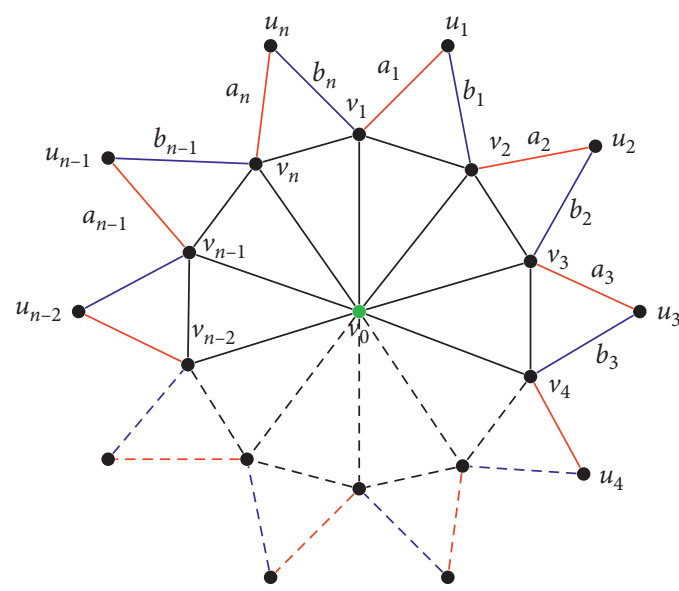

FIGURE 26: The graph $\mathrm{SF}_{n}$ with ordinary labeling.

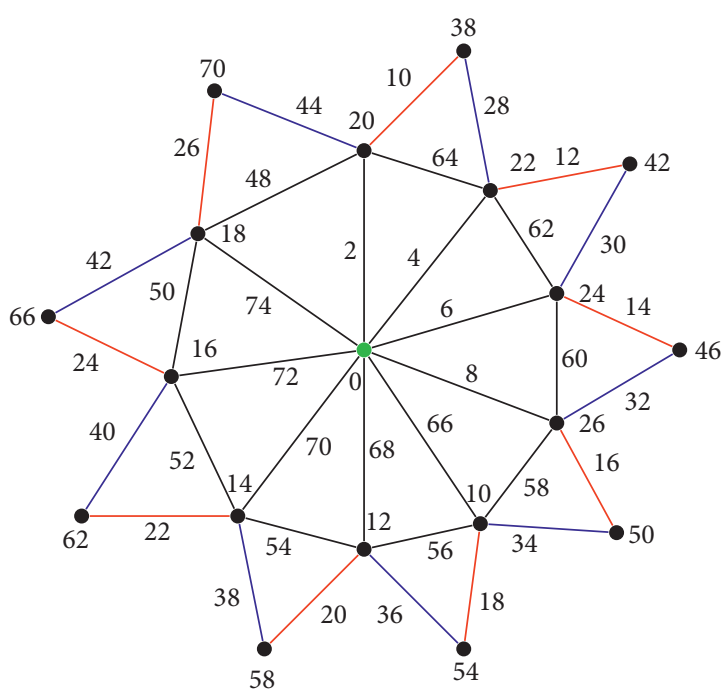

(a)

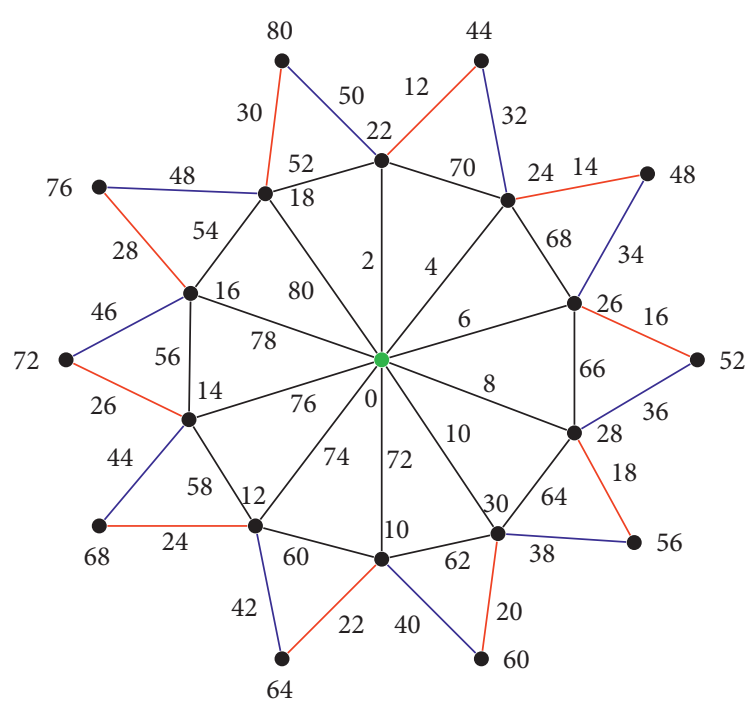

(b)

FIGURE 27: (a) 2-edge even graceful labeling of $\mathrm{SF}_{9}$. (b) 2-edge even graceful labeling of $\mathrm{SF}_{10}$.

Since

$$
\begin{aligned}
& f^{*}\left(v_{i}\right)= {\left[f\left(a_{i}\right)+f\left(b_{i-1}\right)+f\left(v_{0} v_{i}\right)+f\left(v_{i} v_{i+1}\right)+f\left(v_{i} v_{i-1}\right)\right] \bmod (8 n+2), } \\
& f^{*}\left(v_{i}\right)=\left\{\begin{array}{l}
(2 n+2 i) \bmod (8 n+2), \quad \text { if } i=1,2,3, \ldots, \frac{n-1}{2}, \\
(2 i) \bmod (8 n+2), \quad \text { if } i=\frac{n+1}{2}, \frac{n+3}{2}, \ldots, n .
\end{array}\right.
\end{aligned}
$$

Hence, the labels of the vertices $u_{1}, u_{2}, u_{3}, \ldots, u_{n-1}, u_{n}$ are $4 n+2,4 n+6,4 n+10, \ldots, 8 n-6,8 n-2$, respectively, and the labels of the vertices $v_{1}, v_{2}, \ldots, v_{(n-3) / 2}, v_{(n-1) / 2}$ are $2 n+2,2 n+4, \ldots, 3 n-3,3 n-1$, respectively. Also, the labels of the vertices $v_{(n+1) / 2}, v_{(n+3) / 2}, \ldots, v_{n-1}, v_{n}$ are $n+1, n+3, \ldots, 2 n-2,2 n$, respectively, and these are all even and distinct numbers. Thus, the sunflower planar graph, $\mathrm{SF}_{n}$, has 2-edge even graceful labeling.

Illustration. In Figure 27, we present 2-edge even graceful labeling of $\mathrm{SF}_{9}$ and $\mathrm{SF}_{10}$. 


\section{Conclusions}

Graph labeling has become a large and rich branch of various research studies in graph theory. It has enormous applications in many disciplines, like coding theory, X-rays, radar, communication networks, astronomy, and communication network. In this paper, we have extended the definition of edge even graceful labeling to $r$-edge even graceful labeling and strong $r$-edge even graceful labeling. We have obtained the necessary conditions for path-related graphs such as path graph $P_{n}$ when $n$ is odd, double star graph, ladder and diagonal ladder graphs, and tortoise graph and cycle-related graphs such as helm graph, crown graph, sunflower graph, and sunflower planar graph to be an $r$-edge even graceful graph. The minimum number $r$ for which these graphs have an $r$-edge even graceful labeling was found.

\section{Data Availability}

The data used to support the findings of this study are included within the article.

\section{Conflicts of Interest}

The authors declare that they have no conflicts of interest.

\section{Authors' Contributions}

All authors read and approved the final manuscript.

\section{References}

[1] G. S. Bloom and S. W. Golomb, "Applications of numbered undirected graphs," Proceedings of the IEEE, vol. 65, no. 4, pp. 562-570, 1977.

[2] J. Gross and J. Yellen, Graph Theory and its Applications, CRC Press, London, UK, 1999.

[3] B. D. Acharya, S. Arumugam, and A. Rosa, Labeling of Discrete Structures and Applications, pp. 1-14, Narosa Publishing House, New Delhi, India, 2008.

[4] S. P. Lo, "On edge-graceful labeling of graphs," Congruent number, vol. 50, pp. 231-241, 1985.

[5] A. Solairaju and K. Chithra, "Edge - odd graceful graphs," Electronic Notes in Discrete Mathematics, vol. 33, pp. 15-20, 2009.

[6] M. R. Zeen El Deen, "Strong k-edge odd graceful labeling of graphs," International Mathematical Forum, vol. 13, no. 8, pp. 393-405, 2018.

[7] S. N. Daoud, "Edge odd graceful labeling of cylinder and torus grid graphs," IEEE Access, vol. 7, 2019.

[8] A. Elsonbaty and S. N. Daoud, "Edge even Graceful labeling of some path and cycle- related graphs," Ars Combinatoria, vol. 130, pp. 79-96, 2017.

[9] A. A. Elsonbaty and S. N. Daoud, "Edge even graceful labeling of cylinder grid graph," Symmetry, vol. 11, no. 4, p. 584, 2019.

[10] S. N. Daoud, "Edge even graceful labeling of polar grid graphs," Symmetry, vol. 11, no. 1, p. 38, 2019.

[11] M. R. Zeen El Deen, "Edge-even graceful labeling of some graphs," Journal of Egyptian Mathematical Society, vol. 27, p. 20, 2019.
[12] M. R. Zeen El Deen and N. A. Omar, "Further results on edge even graceful labeling of the join of two graphs," Journal of Egyptian Mathematical Society, vol. 28, p. 21, 2020.

[13] M. R. Zeen El Deen, "Edge- $\delta$-graceful labeling for some cyclic-related graphs," Advances in Mathematical Physics, vol. 2020, Article ID 6273245, 19 pages, 2020.

[14] J. A. Gallian, "A dynamic survey of graph labeling," The Electronic Journal of Combinatorics, vol. 1, 2015.

[15] J. A. Bondy and U. S. Murty, Graph Theory, Springer, Berlin, Germany, 2008. 